Version: Postprint (Accepted Manuscript)

2016

\title{
Stridulation of the Clear-wing Meadow Katydid Xiphelimum amplipennis, adaptive bandwidth
}

Glenn K. Morris, Holger Braun, and Christian S. Wirkner

Funding: Study supported by the Natural Sciences and Engineering Research Council of Canada (NSERC) under grant 4946 to Glenn Morris.

Permanent link of this paper: http://hdl.handle.net/1807/96186

\section{Important Notes}

Always cite the Version of Record (VoR: final publisher's version) so that the author(s) will receive recognition through services that track citation counts, e.g., Scopus. When you are unable to access the VoR, the citation needs to include the word, Postprint (Accepted Manuscript).

Visit Publisher's Site for the VoR: https://doi.org/10.1080/09524622.2016.1138883 


\title{
Stridulation of the Clear-wing Meadow Katydid Xiphelimum amplipennis, adaptive bandwidth
}

\author{
Glenn K. Morris ${ }^{1^{*}}$, Holger Braun ${ }^{2}$ and Christian S. Wirkner ${ }^{3}$ \\ ${ }^{1}$ Department of Biology, University of Toronto at Mississauga, 3359 Mississauga Rd, Mississauga ON, L5L1C6 Canada \\ ${ }^{2}$ División Entomología, Museo de La Plata, Universidad Nacional de La Plata, Paseo del Bosque s/No, 1900 La Plata, Argentina \\ ${ }^{3}$ Universität Rostock, Institut für Biowissenschaften Allgemeine und Spezielle Zoologie, Universitätsplatz 2, 18055 Rostock, Germany \\ Research conducted: Estación Centro de Investigaciònes Ecológicas Subtropicales \\ *Corresponding author. Email: glenn.morris@utoronto.ca
}

\begin{abstract}
Rubbed wings, analysed calls and peculiar sound generator structure in males of a conocephaline katydid, Xiphelimum amplipennis, give insight into the making of broadband spectra. High shear forces are indicated by a robust forewing morphology. Intensity is high for frequencies in a 20-60 $\mathrm{kHz}$ ultrasonic band. Besides a typical katydid sound-radiating mirror and harp, this insect has a long costal series of semitransparent specular sound radiators. These wing cells are loaded behind by an enlarged and partitioned subwing air space.

Calls repeat steadily with five different time-domain sound elements. Distinctive spectra are associated with two of these, giving stepwise frequency modulation that combines to create the exceptionally wide spectral breadth. Broadcast sound levels at $10 \mathrm{~cm}$ dorsal, right and left, are near $100 \mathrm{~dB}$. Costal wing-cell sound radiation was explored by loading the costal 'speculae' with wax. This produced almost no decrease in lateral sound levels, but did alter spectral content. Apparently this insect's costal region both baffles and radiates. The species lives at high densities in cluttered vegetation and sound signal attenuation should code via spectral shape for distance ranging.
\end{abstract}

\section{KEYWORDS}

katydid, sound, song, baffle, bandwidth, spectrum, sound level, range, localization, ultrasonic

\section{Introduction}

Xiphelimum amplipennis Caudell, 1906 (Fig. 1) is a 'meadow katydid' in the tribe Conocephalini Burmeister, 1838. It was first found in Paraguay, Caudell's series being 7 males, (Rehn 1907). It was also reported from (probably) NE Argentina by Piran in 1942 and then from SE Brazil, renamed in error as Tympanotriba vittata Piza, 1971. The species' closest tettgoniid relatives are probably Orchelimum spp. (Caudell 1906).

During the southern-hemisphere summer of 2012, this species was the dominant singer in the subtropical forest of Argentina's Iguazú National Park. High-density populations of steadily calling males were heard day and night from understorey 'cluttered' vegetation (Fig. 2) in forest 
clearings and along paths. Some males sang amid the roar of the nearby Iguazú cataracts. This insect stridulates, as do other katydids, using a tegminal generator of modified forewings (Gwynne 2001). We set out to record and study its stridulation.

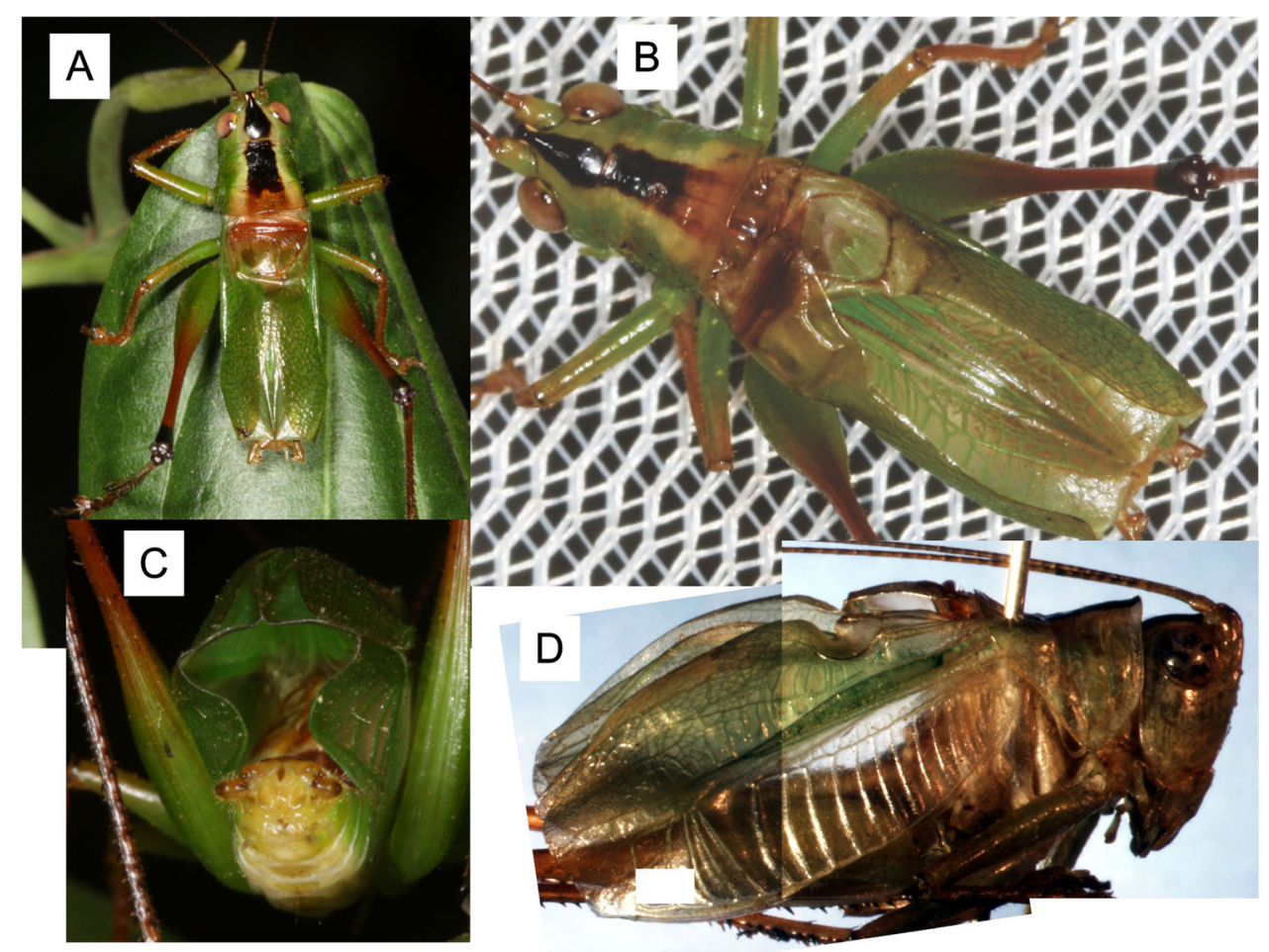

Fig. 1. X. amplipennis adult male. A. Silent perched on a leaf, mesothoracic wings (tegmina) flexed against back. B. Stridulating with canted tegmina; prominent convex metathoracic wings adjoin in midline between tegmina. C. Rear opening of subalar chamber, framed by metawing tips above, fluted tegmina tips laterally. D. Lateral aspect collage of backlit male shows steep-sloped abdomen behind semitransparent costal cell series.

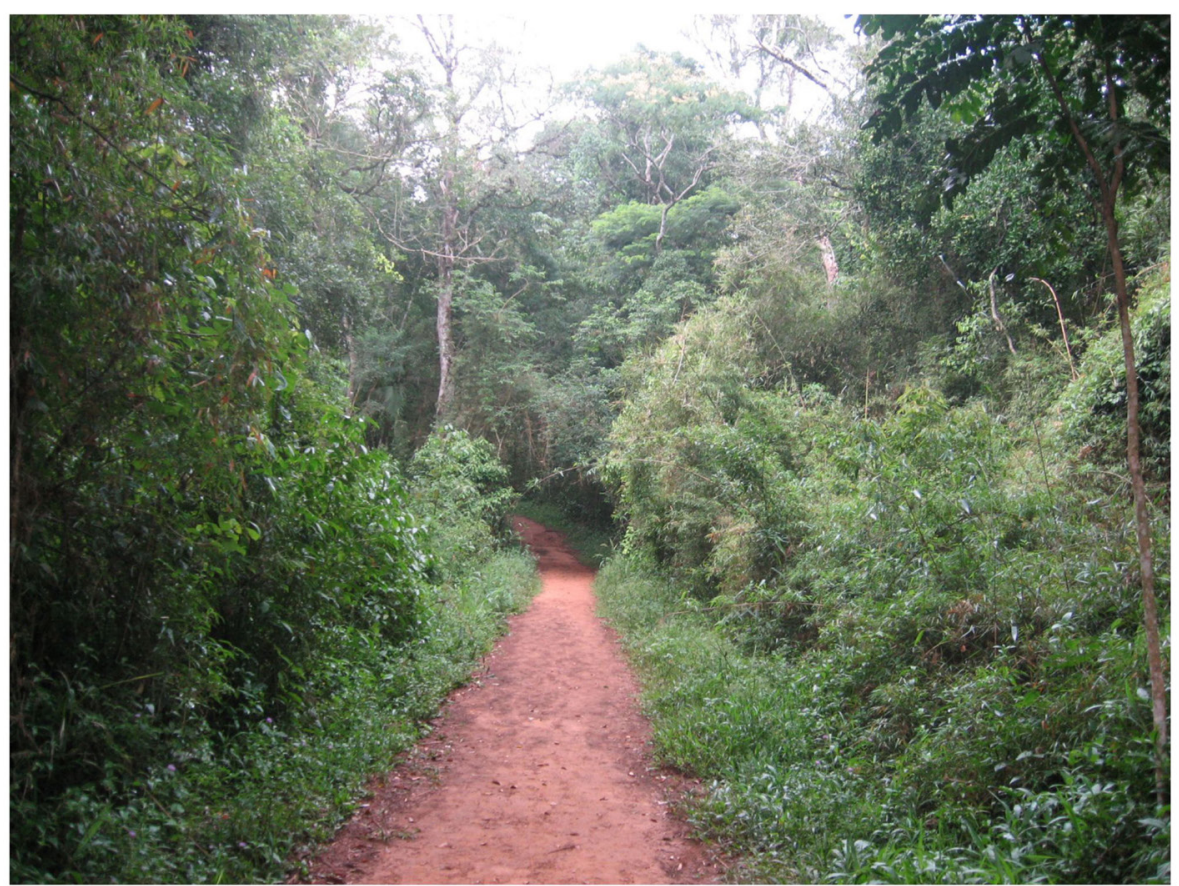

Fig. 2. Habitat of $X$. amplipennis. Cluttered sound-attenuating vegetation bordering Sendero Macuco near CIES (Centro de Investigaciones Ecológias Subtropicales) field station, northern Argentina, the cluttered habitat of $X$. amplipennis. 
Many katydids produce tonal (resonant) spectra, dominated by a single narrow high-Q peak carrier frequency or its harmonics (e.g., Montealegre \& Morris 1999). Meadow katydids, appear to be specialists in broadened spectra, emitting many carrier frequencies simultaneously across a wide band. For example, some North American Conocephalus spp. show an ultrasonic bandwidth of $>20 \mathrm{kHz}$, from about $28-50$ (Morris \& Fullard 1983).

As we recorded and began to analyze the song of $X$. amplipennis we were surprised by the breadth of its band spectrum. Almost all spectral frequencies between 20 and $60 \mathrm{kHz}$ are of high intensity, i.e., this insect has an ultrasonic spectrum bandwidth of $>50 \mathrm{kHz}$. We were puzzled by the morphology of its tegminal generator, unusual among katydids, and saw these morphological peculiarities as illustrating how a generator might be adapted to make a broader spectrum.

The $X$. amplipennis sound generator has the same basic working parts as those of other katydids, but adds some odd features. In a 'typical' katydid generator the left tegmen bears a ventrally toothed transverse vein (file), engaged by an edge of the right tegmen (scraper). File and scraper serve to multiply sound frequencies (Michelsen 1983): thoracic flight muscles move the tegmina, drawing the scraper to and fro along the file. A series of scraper-on-tooth shear forces impart oscillations to thin-membraned sound-radiating wing cells called speculae: "glassy areas ...that serve as sounding boards" (Torre-Bueno 1962). Speculae, prominent on the right tegmen as the 'mirror' and 'harp', are usually confined to the tegmen's anal region. Relatively low frequencies of muscle contraction are 'multiplied' to the higher frequencies of airborne sound by the file and scraper.

Importantly, all katydid tegminal generators include body spaces -- a subtegminal space below, against the back, a subnotal space above, contained by the rearward jutting pronotum. These air spaces are critical in katydid sound-making, for they load the speculae with sound radiation impedances (Michelsen 1983). Tegminal generators are also seen as dipole sound sources (Fletcher 1992; Braun, Chamorro-Rengifo \& Morris 2009), i.e., a cantilevered oscillating diaphragm radiating sound to both of its sides. In most katydids the anterior or costal margin of the tegmen deflects down upon the singer's sides. This deflected costal region, anterior to the main supporting compound vein ( $\mathrm{S} c+\mathrm{R}$, see below), is relatively thick, flexible rather than stiff. It appears adapted to act as a baffle, limiting short-circuiting inefficiences at the diaphragm edges (Fletcher 1992, p. 238).

Four features go well beyond 'basic working parts' in the generator of $X$. amplipennis,1) a 'costal cell series' 2) an enlarged space beneath the wings, 3) body length metawings that 4) partition the enhanced space. The costal cell series is an array of large semitransparent wing cells on the anterior margin of the tegmen (Fig. 1D, Fig. 4A) backed by greatly enlarged air space (Fig. 6C,D); backlit one sees through this insect to the steeply sloped line of its back, inspiring the common name 'Clear-wing katydid'. The tegminal costal area, normally a baffle, appears in $X$. amplipennis to involve sound-radiating speculae. Is the costal array a structural adaptation for sound radiation, contributing more and different frequencies over a wider band? How might greater space contribute to a wider band spectrum?

To answer such questions we studied $X$. amplipennis' wing morphology, using both orthodox light microscopy and laser tomography, contrasting it with the more typical generator, of Sphagniana sphagnorum (F. Walker, 1869). We present results of calling-song digital recordings and analysis (time domain, frequency domain, broadcast field) for 14 males. We specifically compared lateral sound levels looking for radiation enhancement. By wax-loading we tested whether the costal cell series contributes importantly to enhance sound radiation in this species, adding either intensity or spectral breadth or both. 


\section{Methods}

\section{Study insect}

During February/March 2012 adult male specimens of $X$. amplipennis were collected in Iguazú National Park, Argentina, from dense herbaceous vegetation along the Sendero Macuco (Fig. 2), a wide footpath near the CIES (Centro de Investigaciones Ecológias Subtropicales) field station. The insects were maintained individually in roofed, floorless, cylindrical all-Aluminum screen cages, diameter $\sim 5 \mathrm{~cm}$, height $\sim 10 \mathrm{~cm}$, screen mesh 18 strands per inch, the screen bent and stapled to shape, pinned down on a sound-absorptive foam block. (The screen is assumed to be acoustically neutral.) The insects were given small pieces of apple and misted often with water.

Specimens were photographed and drawn under a dissection microscope. For two males tegminal morphology was studied (by C.S.W.) using tomography. From these two specimens we obtained an estimate of cuticular thicknesses (mirror, costal cells etc.): wings were fixed in Bouin's fixative; subsequently parts were dehydrated in ethanol and after an intermediate step employing epoxypropane, embedded in Araldit epoxy resin under vacuum. Serial semithin sections $(1 \mu \mathrm{m})$ were made with a Leica Ultracut UCT ultramicrotome using glass or diamond knives. The sections were stained with a mixture of $1 \%$ azure II and $1 \%$ methylene blue in an aqueous $1 \%$ borax solution for 10 sec. at $80-90^{\circ} \mathrm{C}$.

\section{Forewing morphology}

Designation of wing veins follows Béthoux (2012) and the reader can refer to Figs 3-5 in which veins, vein-delimited wing cells and other generator parts are labelled. Comparison helps make the structural peculiarities of $X$. amplipennis clearer, so the generator of another (also nonvolant) species, S. sphagnorum, is illustrated. S. sphagnorum males are brachypterous; $X$. amplipennis males are macropterous; but for both species their tegmina function in sound generation and not at all in flight. References to tegmen aspect, anterior and posterior, are relative to an extended tegmen.

Two compound-vein landmarks are used to designate tegminal topography: $\mathrm{Sc}+\mathrm{R}$ and $\mathrm{M}+\mathrm{CuA}$ (Figs 3, 4). These veins demarcate three wing areas proximal to the wingbase: anal, costal and mediocubital. The acoustically modified anal area, the site in katydids of files, scrapers and wing-cell sound radiators (see below), is that posterior to $\mathrm{M}+\mathrm{CuA}$. CuA separates from $\mathrm{M}$ distad and angles toward the posterior margin, approaching the cubitoanal emargination (Fig. 3B, cae): the CuA's path marks the rearward border of the anal area. The costal area is the forewing anterior to $\mathrm{Sc}+\mathrm{R}$, a region turned down along the insect's side; functionally the costa acts as a sound baffle (see below). The area between the costal and anal areas, i.e., between $\mathrm{Sc}+\mathrm{R}$ and $\mathrm{M}+\mathrm{CuA}$ and near to the wingbases, is termed mediocubital. The fourth tegminal area, the distal remainder of the tegmen, is dominated by archedictyon (primitive vein network, Torre-Bueno 1962) and is called here the distal region.

The scraper (s, Fig 4B) is an upward projecting ridge on the right tegmen's posterior margin which engages file teeth from below. The region between the scraper and the rim of the mirror (m) is the scraper linkage (Fig. 4B); it is a mechanically critical region whose springiness greatly affects mechanisms of tooth engagement and power amplification in different tettigoniid species (Bennet-Clark 1998, Montealegre \& Mason 2005, Montealegre et al. 2006, Patek et al. 2011).

Tegminal stridulation arises out of thoracic distortion by indirect flight muscles. The canted tegmina are pulled against each other as axillary sclerites at the wing bases change linkage (Gutierrez 2015). To resist these transverse action forces, the proximal posterior margin of both 

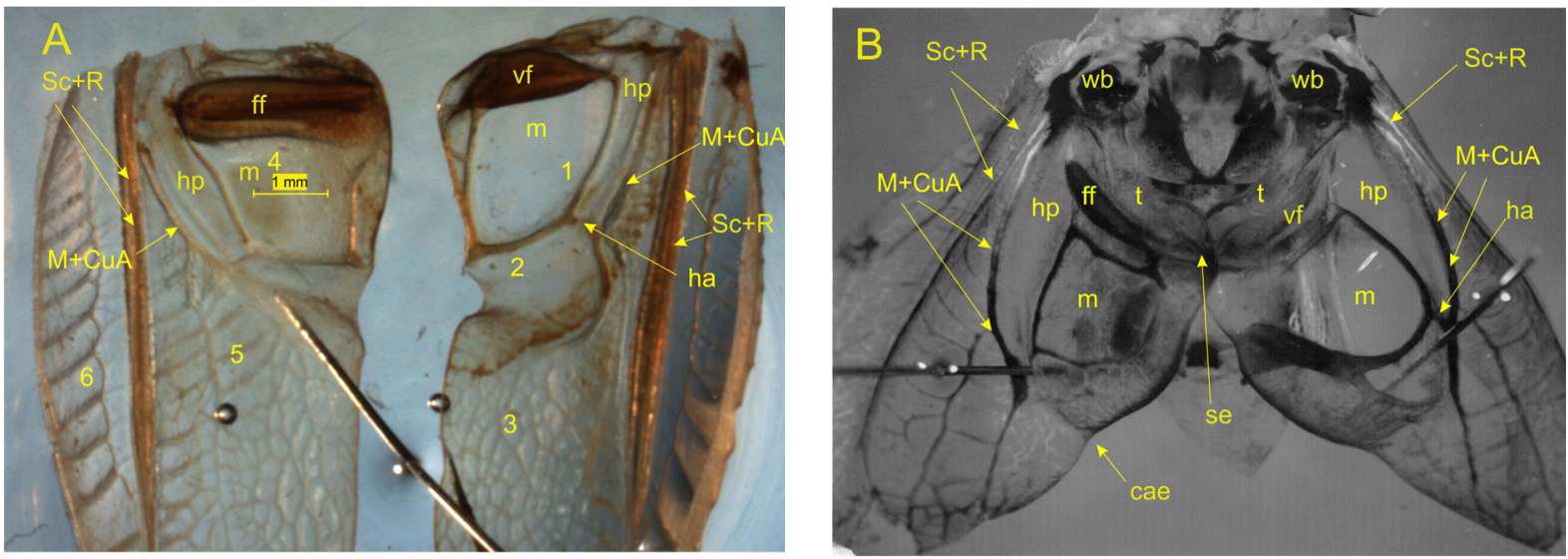

Fig. 3. Tegmina of $X$. amplipennis (A) and S. sphagnorum (B), viewed dorsally, cleared, pinned. Numbers 1-6 (A) indicate regions sampled for cuticle thickness (Table 1). Tegmina in B with engaged scraper (se) distad on file. Left tegmen functional files (ff) well developed both species, robustly curved upon itself in X. amplipennis. Right-tegmen file of $X$. amplipennis (vf) large, swollen, only nominally 'vestigial', compares to modest structure of S. sphagnorum. Legend: cae, cubito-anal emargination; ff, functional file; ha, harp handle; hp, harp; $\mathrm{M}+\mathrm{CuA}$, median plus cubitus anterior; $\mathrm{Sc}+\mathrm{R}$, subcosta plus radius; $\mathrm{m}$, mirror; $\mathrm{t}$, truss; vf, vestigial file; wb, wing base.
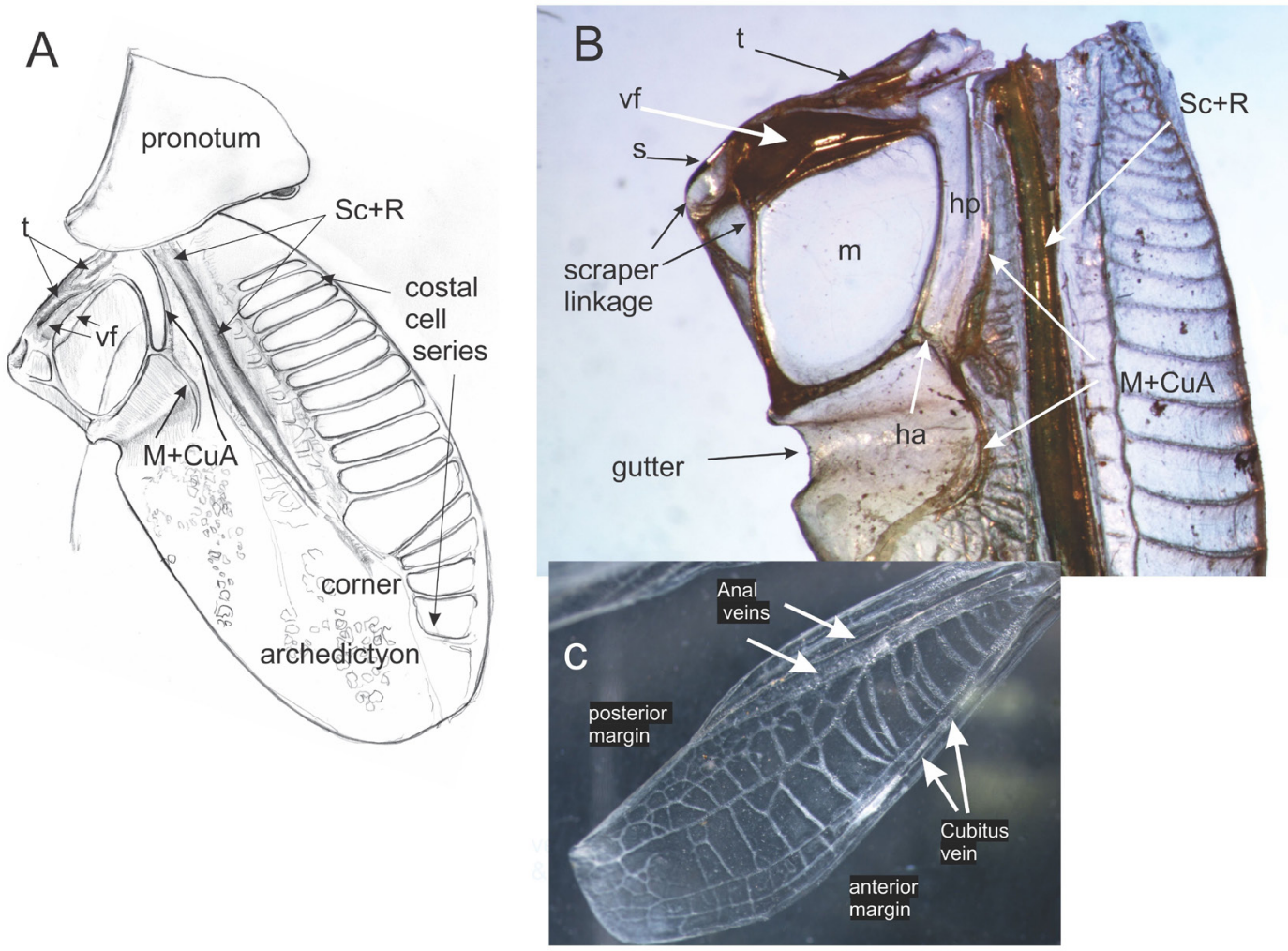

Fig. 4. X. amplipennis wings. A. Dorsolateral pronotum and dorsolateral aspect right tegmen: major cantilevered compound vein $\mathrm{Sc}+\mathrm{R}$, truss ( $\mathrm{t}$ ), adjoining robust 'vestigial' file ( $\mathrm{vf}$ ). Anal wing region is proximal to wing base and posterior to $\mathrm{M}+\mathrm{CuA}$; elaborated costal cell series attains rear 'corner': archedictyon is primitive wing cuticle. B. Anal wing region set off by $\mathrm{M}+\mathrm{CuA}$; gutter indicates elevation above dorsum. Legend: hp, harp; ha, harp handle; s, scraper. C. Ventral aspect cleared right metathoracic wing transmitted light; note absence of costal area, prominent peripheral cubitus and anal veins stiffen wing edges. 
tegmina is modified into a strut or 'beam' of close anal veins, called here a truss in reference to how the veins are deployed within the strut (t, Fig. 4).

In the anal area of the right tegmen of most katydids are two transparent sound-radiating speculae: "sounding boards" (Torre-Bueno 1962), a variably rounded to rectangular mirror is cradled by an elongate crescentic harp (m, hp, Figs 3, 4). The mirror shares one vein with the harp $\left(\mathrm{CuPa}_{\alpha 2}\right.$, Cubitus posterior anterior alpha 2, Bethoux 2012). The harp is bounded anteriorly by $\mathrm{M}+\mathrm{CuA}$ and divided middlewise by a fading $\mathrm{CuPa}$ (Bethoux 2012). The harp's 'handle' is a short crossvein joining the mirror and $\mathrm{CuA}$.

Table 1. Total thickness measures (microns) of sectioned tegminal regions (rt: right tegmen; lt: left tegmen) for a $X$. amplipennis male specimen. REGIONS: Fig. 3B (1-6). RELATIVE: thicknesses relative to mirror mean of 2.35 microns.

\begin{tabular}{|l|r|r|r|r|}
\hline REGION & MEAN & RANGE & $\mathrm{N}$ & RELATIVE \\
\hline 1. MIRRORrt & 2.35 & $1.93-2.64$ & 9 & -- \\
\hline 2. GUTTERrt & 6.01 & $5.41-7.13$ & 12 & 2.6 \\
\hline 3. DISTALrt & 11.92 & $7.99-18.16$ & 8 & 5.1 \\
\hline 4. MIRRORIt & 5.09 & $4.74-5.70$ & 3 & 2.2 \\
\hline 5. DISTALIt & 26.17 & $22.9-28.2$ & 3 & 11.1 \\
\hline 6. COSTALIt & 11.3 & $10.15-12.76$ & 8 & 4.8 \\
\hline
\end{tabular}

\section{Call recording, sound level measures, spectral averaging}

For each of 12 males, from five aspects (dorsal, lateral right, lateral left, anterior, posterior) at a $10-\mathrm{cm}$ distance, we obtained sound-level calibrated call recordings, each of 5-10 s duration. The longest wavelengths emitted by $X$. amplipennis are those of its audio peak near $7-8 \mathrm{kHz}$ (see below), $\sim 4.6-\mathrm{cm}$ wavelength. We took the length of two such waves as marking the transition from near to far field. Our 10-cm working distance for sound-level recordings puts the microphone just at the start of the far field for the lowest carrier frequencies of this species.

Recordings were made using a $1 / 4$ " condenser microphone (40BD, G.R.A.S. Sound and Vibration) with a preamplifier (G.R.A.S. 26CF). Microphone, adapter and preamplifier total 16 $\mathrm{cm}$ in length $\sim 2 \mathrm{~cm}$ diameter. Microphone output went to a digitizer, Photon II Dynamic Signal Analyzer (Novel Dynamics), thence to the application RTPro 6.3491 (LDS Dactron, USA) running on a notebook computer. Sound frequencies from $<1 \mathrm{kHz}$ to beyond $70 \mathrm{kHz}$ are treated uniformly by this equipment. We obtained levels at five aspects: frontal, rear, dorsal, right and left lateral. Recordings were achieved opportunistically over a period of two weeks, depending on which, and when, individuals were inclined to stridulate.

RTPro converts a computer into a sound level meter, calibrated for $\mathrm{dBPa}$ rms re 0.00002 $\mathrm{dyne} / \mathrm{cm} 2$. The y axis of a spectral display appears in $\mathrm{dBPa}$ rms-specific spectral component readings, but is also available as a single $\mathrm{dBPa}$ rms value for an entire spectrum (RTPro 'numeric display'); the latter are referred to here as 'all-spectrum' readings.

The microphone barrel was adjustably clamped to a wooden-dowel support stand. The microphone tip was set $10 \mathrm{~cm}$ distant from the specular region of the insect, aligned with its long axis normal to the relevant body plane. For lateral recordings, both right and left, the microphone 
long axis was normal to the sagittal midplane of the insect's body; for frontal and rear recordings it was normal to the transverse body plane; for dorsal recordings it was normal to the frontal plane. Sound levels on the G.R.A.S. microphone pre-amplifier were set to boost by $20 \mathrm{~dB}$. A small tape rule, or initially a thin protruding wire taped to the microphone barrel, aided in visual estimations of microphone tip to singing-insect distance.

Early recordings taken at a sampling rate of 192 kilosamples per sec (e.g., specimen 13 Figs 7C, 8) established no appreciable energy in the insect's call beyond $70 \mathrm{kHz}$. Thereafter all recordings were made at 131 kilosamples per sec. Recording temperatures in the laboratory building varied between 24 and $30.5^{\circ} \mathrm{C}$, a variation disregarded in calculating means.

\section{Spectral analysis of natural singers}

We used the visual spreadsheet DADiSP (DSP Development ver. 6.5) to carry out Fast Fourier Transform calculations on time-domain samples from the recordings originally obtained with RTPro. Power spectral densities for trains $2+3$ and train 4 , were calculated upon a time sample of 4096 values using a Welch moving average. Each time sample is divided into 25 segments of 128 points each, where each segment overlaps the previous by 64 points. Signals were high-pass filtered at $200 \mathrm{~Hz}$.

From each recording of each specimen, at each of 5 different aspects, we selected one complete phonatome group (PG). A time-domain sample of 16384 points was positioned to centre on and symmetrically encompass this PG. Fore and aft parts of trains 1 and 5 only sometimes accompanied, but the time sample always included all of both major trains. An FFT power spectrum of 6400 lines was calculated.

Using RTPro we also averaged FFT spectra over either 10 or 20 frames, by amplitude pretriggering at $-10 \mathrm{~ms}$ each frame of a complete single song.

\section{Statistical analysis}

We tested the null hypothesis of no effect of aspect on natural sound levels using a repeated measures ANOVA. For each calculated FFT we obtained the dBPa rms value for the overall spectrum (an 'all-spectrum' reading) using RTPro 'numeric display'. In a few instances where the recording distance was slightly other than $10 \mathrm{~cm}$, the measured reading was corrected mathematically to a $10-\mathrm{cm}$ distance per inverse spreading.

\section{Loading experiments}

We looked for effects on sound levels and spectra of loading the costal wing areas with low melting-point wax. When all his 'natural' records from the five aspects were complete, a specimen became available for this experimental modification. Wax-treated stridulating specimens were recorded as opportunity provided, at the same aspects and standard $10-\mathrm{cm}$ distances as for loadfree singers.

Wax was applied to wing surfaces using a custom-made heating device. A standard walladapter power supply rated at $12 \mathrm{~V}$ supplied power to the two leads of a tip made of standard 1/4-watt carbon film. One lead was bent into a loop to act as a reservoir for the melted wax, the remainder, wrapped around the body of a resistor (277 ohms) took up the resistor's dissipated heat and conveyed it into the reservoir. One person gently hand-held an insect, while another applied melted wax by drawing the reservoir along a tegminal region. Slightly more than $2 / 3$ of 
the costal area was waxed, not the entire cell series. Wax loadings could not be easily removed, so loading of specimens was treated as an irreversible and incremental process. Low sample size precluded statistical analysis of the waxing experiments, and observed effects are presented as preliminary.

For each of six singers, tegminal costal cells were wax-loaded one side (4 insects on left, 2 on right) and their songs compared for before and after effects (sound levels, spectral peaks) upon ipsilateral spectra. Three of these six specimens progressed to testing the effects of having both right and left costae waxed. Sound level measures were 'numeric display' (= 'all-spectrum' see above) and based upon one complete time-centred phonatome group (i.e., one song). Spectral comparisons were each based upon a time sample of four consecutive calls. The time sample was high-pass filtered at $200 \mathrm{~Hz}$ and the resulting power spectral density displays Welch smoothed. This Welch moving average was divided into 25 segments of 128 points each, where each segment overlapped the previous by 64 points.

For two other specimens, wax was applied to the metathoracic wings where they are exposed contiguous in the midline; the wax had the effect of fusing the hind wings, as well as increasing their mass. For one other specimen we recorded the animal singing with most of the subalar cavity open above as a result of excising its metathoracic wings with microscissors.

\section{Results}

\section{Generator morphology}

$X$. amplipennis' generator (Figs 3A, 4) differs from that of typical katydids, e.g., from that of $S$. sphagniana (Fig. 3B), in both strength and enclosed space. Veins are very enlarged and there is a great increase in tegminal surface area, containing a greatly increased volume of partitioned subtegminal air space.

\section{Enlarged veins for greater force}

The compound vein $\mathrm{Sc}+\mathrm{R}$ (Figs $4 \mathrm{AB}, 5 \mathrm{D}$ ) is the main cantilevered wing support during stridulation; this vein is more robust in $X$. amplipennis to accomodate the insect's higher wing mass. The scraper linkage of $X$. amplipennis (Fig. 4B) is reduced in comparison to S. sphagnorum (Fig. 3B) (Gutierrez 2015), perhaps making this region stiffer, i.e., affecting springiness (Patek et al. 2011) and power amplification (Bennet-Clark 1998). Greater stiffness would allow for more immediate but lower force translocation to the mirror rim.

The trusses (Figs 3, 4), which serve as opposing canted struts during stridulation, appear equally developed on both tegmina in both species. The tooth-bearing transversely running $\mathrm{CuPb}$ veins (Bethoux 2012), i.e., the file veins, show differences related to force translocation. These differences are katydid-typical for S. sphagnorum (Fig 3B): the left tegmen file (ff) is thick and functional, the right (vf) is undeveloped, aptly termed vestigial or 'secret' (Chamorro-Rengifo et al. 2014).

$\mathrm{CuPb}$ in $X$. amplipennis are remarkably katydid-atypical. In both left and right tegmen a second vein has been incorporated: $\mathrm{CuPa}_{\alpha 2}$ (Bethoux 2012); this combination lends more strength. The left tegmen file vein (ff, Fig. 3A) now appears to curl seamlessly back upon itself, like some cuticular cake decoration. The right tegmen file is differently shaped, fusiform, thickened almost as much as the left, (Fig. 4B). The teeth of this only nominally 'vestigial' file are comparable in 

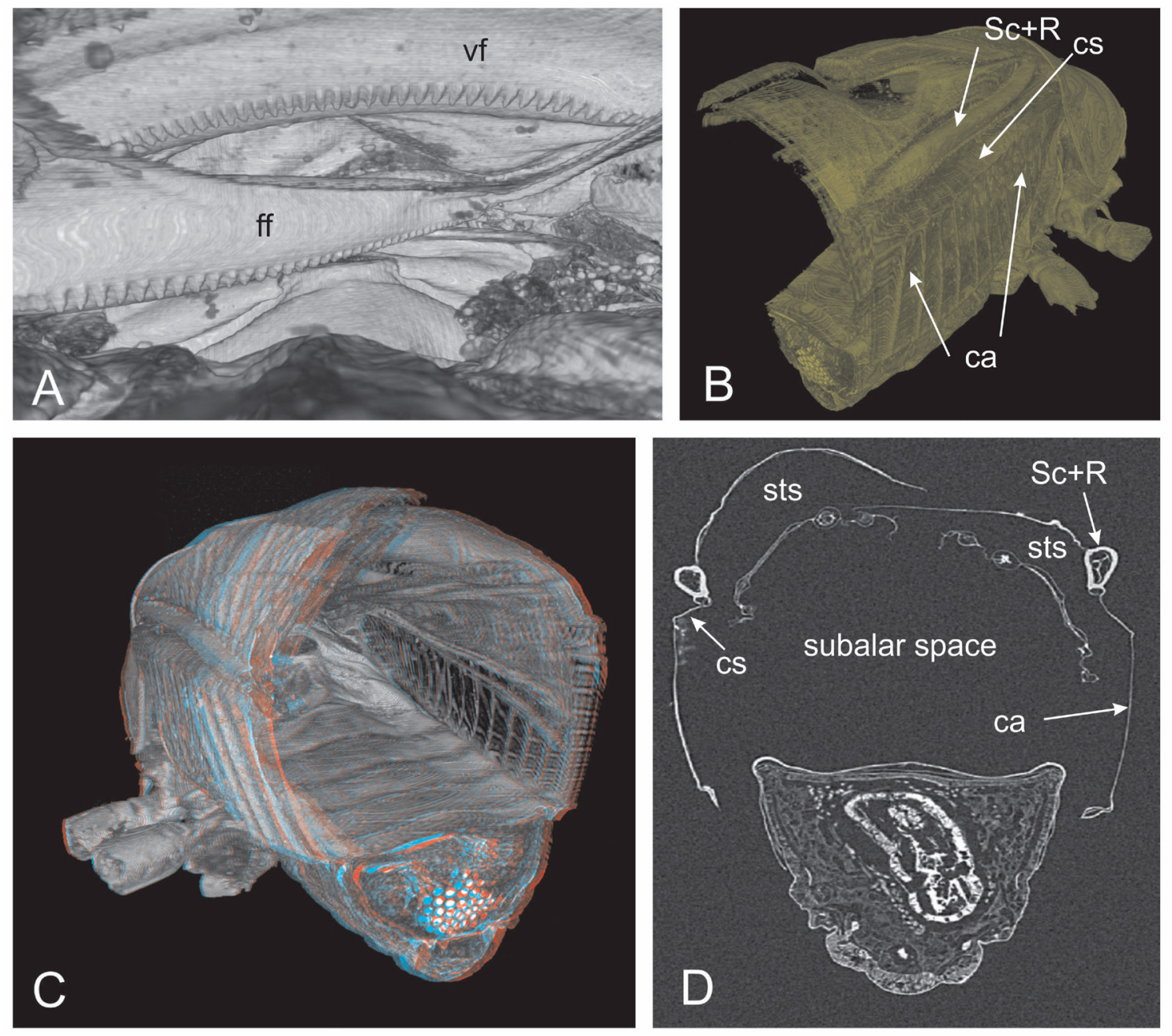

Fig. 5. Microcomputer tomography of X. amplipennis. A. Posterior aspect overlapped tegmina, shows file teeth comparably developed on right vestigial (vf) and left functional (ff) files. B. 3-D scan of thorax and part of abdomen with left body half removed virtually. Prominent $\mathrm{Sc}+\mathrm{R}$ vein cantilevers the tegmen; costal array (ca) lies against the insect's side topped by a costal shelf (cs). C. Complete scan, red/cyan coded (use 3-D goggles): shows possible internal engagement of lateral margins of metawings against $\mathrm{Sc}+\mathrm{R}$. D. Virtual transverse section shows triangular shape of dorsum-flattened abdomen. Beneath the tegmina are two large spaces, partitioned by the metawings (mw): subtegminal (sts) and subalar (sas).

size to those of the functional file (Fig. 5A), seeming to suggest functionality in stridulation (but see below).

\section{Space and surface area}

The subtegminal air cavity typical of katydids is a 'tunnel of air' floored by the dorsum of thorax and abdomen, sided by the costal regions and opening (often) widely rearward above the terminalia, e.g., S. sphagniana (Fig 3B of Morris 2008). For X. amplipennis added 'tunnel' space is apparent via the costal cell series (Fig. 4A) as one views a backlit male with his deeply depressed abdomen (Fig. 1D). The series, right and left, of deep, semitransparent rectangular costal cells gradually increment in size, until reaching a corner (Fig. 4A) marked by a nearly triangular cell (Fig. 4A). These rear corners, left and right, absent in typical katydid tegmina, also add to the volume of the subtegminal space within. A cornice (cs) juts outward below $\mathrm{Sc}+\mathrm{R}$ and the top of the costal 
series, contributing still further to cavity volume. The volume of this 'tunnel' in $X$. amplipennis is also enhanced by the raising of the plane of the anal area, i.e., the plane of the files and speculae (Fig. 3A), creating a plateau that separates itself distad from the archedictyon as a deep gutter (Fig. 4B) just where the $\mathrm{M}+\mathrm{CuA}$ is bending toward the posterior margin of the tegmen (Fig. 4A).

\section{Subtegminal space partitioned into a subalar chamber}

In nonvolant katydids one expects to see the metathoracic wings completely absent or vestigial, but here they are strongly developed arched flaccid (Figs 1B, 4C), reaching the end of the body. Their cord-like veins are gathered toward anterior and posterior margins. $\mathrm{ScR}$ and $\mathrm{Cu}$ are crowded upon the anterior margin, anal veins are grouped toward the posterior. These metawings are tightly
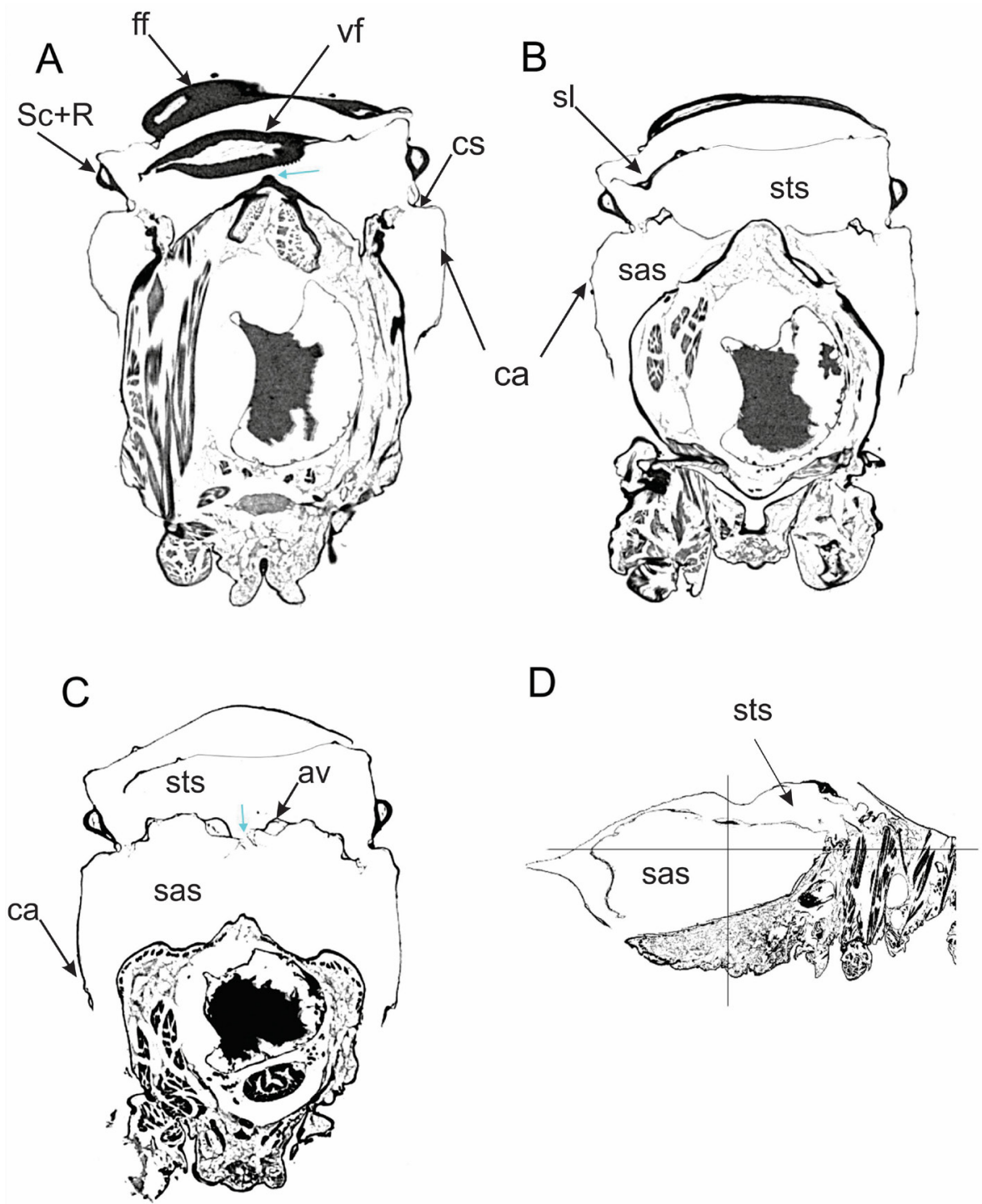

Fig. 6. Sections of $X$. amplipennis. A. Transverse section of thorax just posterior to wing bases; thick-walled (hollow) file veins left (ff) above right (vf). Blue arrow directs to midline projection, rejected as able to engage with vf teeth (see text). B. Transverse section farther posterior showing scraper linkage (sl); note wingpartitioned spaces beneath tegmina: subtegminal space (sts) and subalar space (sas) separated by metawings. C. Section still further back. Blue arrow marks midline appositon of metawing anal veins (av). Costal array (ca) forms lateral walls right and left of subalar space (sas); metawings comprise sas roof, with space above subtegminal (sts). D. Sagittal slightly-off-midline section shows steep downslope of flattened abdomen floor to the subalar space (sas). 
adpressed in the midline during stridulation (Fig. 1B) but are seemingly too flaccid to radiate much sound, their form suggests rather function as an absorber of sound.

The metawings partition off, a rear subalar chamber, by bridging to the inner face of the $\mathrm{ScR}$. The anterior margin of each metathoracic wing, appears shaped to engage with the ipsilateral $\mathrm{Sc}+\mathrm{R}$ vein of the tegmen (Figs $5 \mathrm{C}, \mathrm{D}, 6 \mathrm{~B}$ ). The specimen prepared for tomographic analysis does not actually show these parts engaged, but one can observe in the scans how they might fit. See particularly the transvserse section of Fig. 5D where laterally the left hind wing lies near the main ScR of the left tegmen. We suspect this region adjoins/latches during stridulation, supporting the metawings along their length.

Surface area also relates to macroptery. $X$. amplipennis males are not seen to fly, yet are macropterous, with both tegmina and wings of body length. Macroptery in an animal that does not use its wings for flight should be seen as an acoustic adaptation involving increase in surface area available for possible sound radiation or baffling (see Discussion).

Overall these morphological peculiarities relate to increased area for sound radiation and enhanced volume of loading air masses. To move these additional components requires translocation of greater forces via strengthened veins. These features go toward the making of a higher-impedance generator.

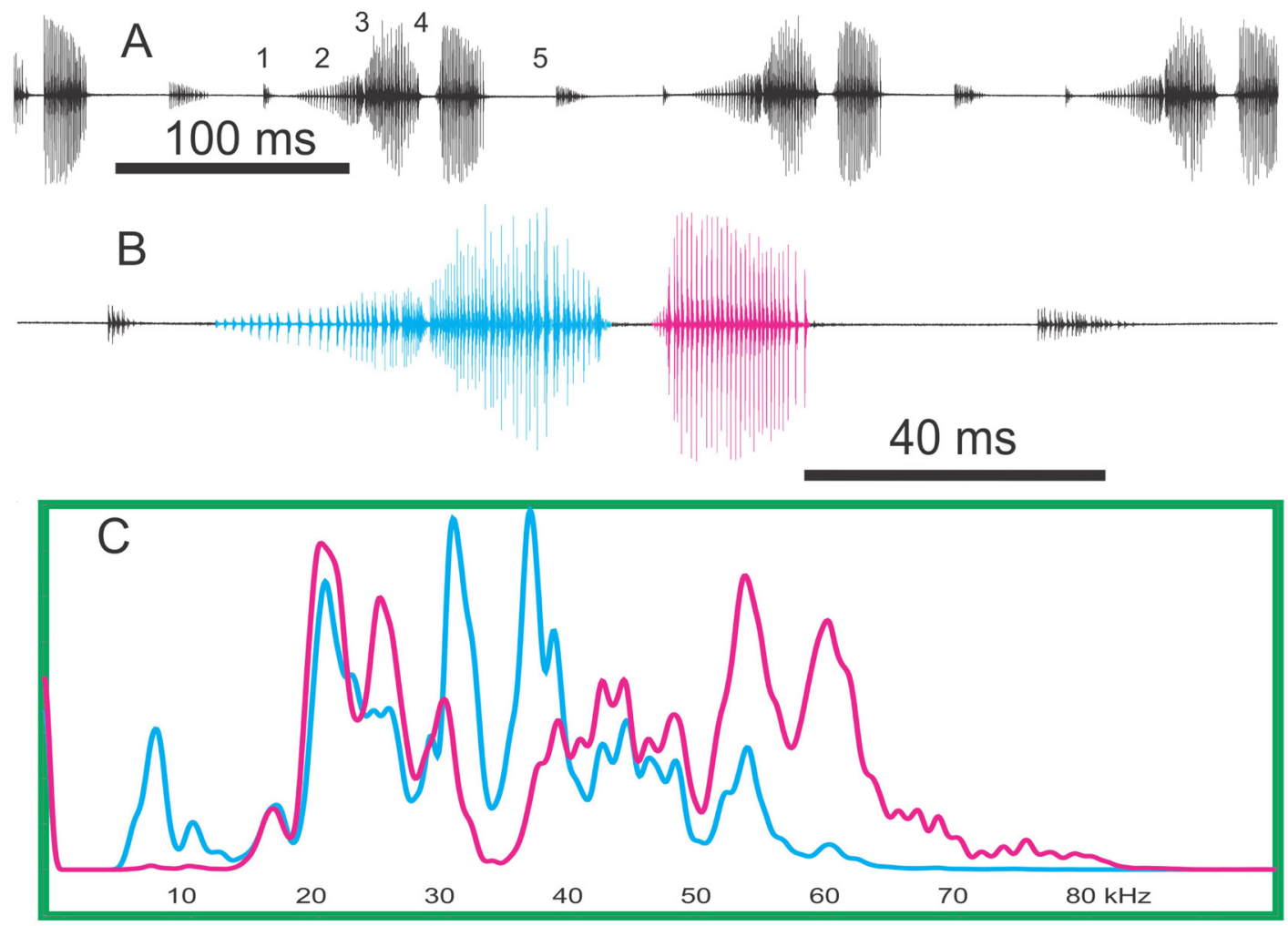

Fig. 7. Time and frequency domain analysis of SN 13, (DADiSP) showing FM. Based on an original recording made at 192000 kilosamples/s $10-\mathrm{cm}$ dorsal aspect $26^{\circ} \mathrm{C}$. A. Time domain record (part of ) 4 calls, two in middle complete; PTG train components numbered 1-5. B. One complete call at higher time resolution, major trains colour coded. C. Welch-smoothed (moving average) power spectral density (psd) estimations comparing major trains ( $2+3$ vs 4). A 6400 -value time sample divided into 25 segments of 256 values each, where each segment overlaps the previous by 128 points; Fast Fourier Transform(FFT) of each segment calculated and averaged. The two song parts produce different spectra. 


\section{Song structure: broadband frequency modulation}

The call/song of a $X$. amplipennis male is readily audible to human ears as a steady series of 'plosive sounds', rather like a tiny one-stroke engine, running minutes at a time. At moderately high temperatures $\left(25^{\circ} \mathrm{C}\right)$ one can easily count these calls and so estimate a call repetition rate of $\sim 6$ per second. Each call is a grouping of 5 elements designated here as pulse trains and arbitrarily numbered 1-5 in Fig. 7A. Each impulse, probably coinciding with passage across one file tooth by the scraper, decays rapidly and a large number of these rapid-decay impulses/pulses give rise to a train with a characteristic overall shape, an 'amplitude envelope'. Fig. 7A shows 2 partial and 2 complete songs, one with its five train types numbered consecutively. In Fig. 7B trains 2 and 3 are blue coded and train 4 is red.

Trains 1 and 5 are relatively faint, brief, and variable, and their pulses decline in amplitude throughout (Fig. 7 A, B) making for a triangular amplitude envelope. Trains $2+3$ and 4 are much longer in duration and much more intense. Train 2's envelope has a right-directed obovate shape, early pulses starting very faintly and very gradually increasing in both amplitude and rate (Fig. 7B). Trains 3 and 4 are maximally intense within the call and of nearly equal duration, the $3^{\text {rd }}$ fusiform, the $4^{\text {th }}$ rectangular, the $4^{\text {th }}$ with a higher pulse repetition rate than the $3^{\text {rd }}$. All these train features, envelopes, durations, changes in pulse rates etc. are relatively stereotyped, repeating among individuals.

For a temperature range of $24-30^{\circ} \mathrm{C}$, we calculated the following averages of time-domain elements (ms, ranges in parens). Song period was 169 (120-233). The first train's duration is quite variable, just a file-touch of a few faint sound pulses, mean $2.4(0.5-5.7)$. Train 5 is also brief, but with more pulses and longer lasting, mean $7.5 \mathrm{~ms}(2.9-16.6)$. Train 2 duration is on average 26.8 $\mathrm{ms}(19.5-32.6)$. The $3^{\text {rd }}$ train $(20.7,16.8-24.7)$ is temporally distinct from the $2^{\text {nd }}$, but sometimes 'only by envelope'; it rises then falls, pulses staying intense throughout. The pulse rate within train 4, calculated upon a count of the number of pulses in a $10-\mathrm{ms}$ interval, is about 1700 per s; in train 3, it is $\sim 2000$. This insect achieves relatively high katydid tooth-contact rates; compared to e.g., <1000 in Conocephalus fasciatus (Morris 1965).

There are two conspicuous downtimes within each song: the first, between train 3 and 4, has a mean duration of $7 \mathrm{~ms}(4.9-10.6)$; the second between 4 and 5, is much longer, mean 29 (23-35.7). Coefficients of variation (CV\%) calculated for these time-domain parameters show the durations of train 3 and 4 and the $4-5$ silent interval to be $14 \%$, substantially less variable than the durations of trains 1 and $5(>50 \%)$.

The most intense frequencies of $X$. amplipennis' song are all ultrasonic, but there is a lowintensity audio peak (mean 8.3, range $7.2-9.8 \mathrm{kHz}$ ) associated only with trains $2+3$. This relatively quiet audio frequency dominates human hearing.

The Welch-smoothed spectra (Fig 7 C) based upon trains $2+3$ and train 4 are colour coded, to show the coinciding upward stepwise frequency modulation (FM). As the insect produces train 4 (Fig. 7C, Fig. 8) the audio peak drops out and higher ultrasonic frequencies, between 40 and $70 \mathrm{kHz}$ (red) dominate. The spectra of trains $2+3$ include the aforementioned audio peak near $8 \mathrm{kHz}$, but also ultrasonic frequencies maximally intense between 20 and $40 \mathrm{kHz}$ (blue, Fig. 7C).

The spectra generated during the song represent a stepwise modulation between trains 2-3 and train 4. They are both low-Qband spectra of large bandwidth and with a high level of intrinsic variability in subpeaks (Fig. 9). A low-intensity audio peak near $8 \mathrm{kHz}$ is a consistent feature of train $2+3$ spectra, and is always absent from the spectrum of train 4 (compare blue and red in Fig. 9). An upward shift into the further ultrasonic occurs with train 4 . There are multiple 


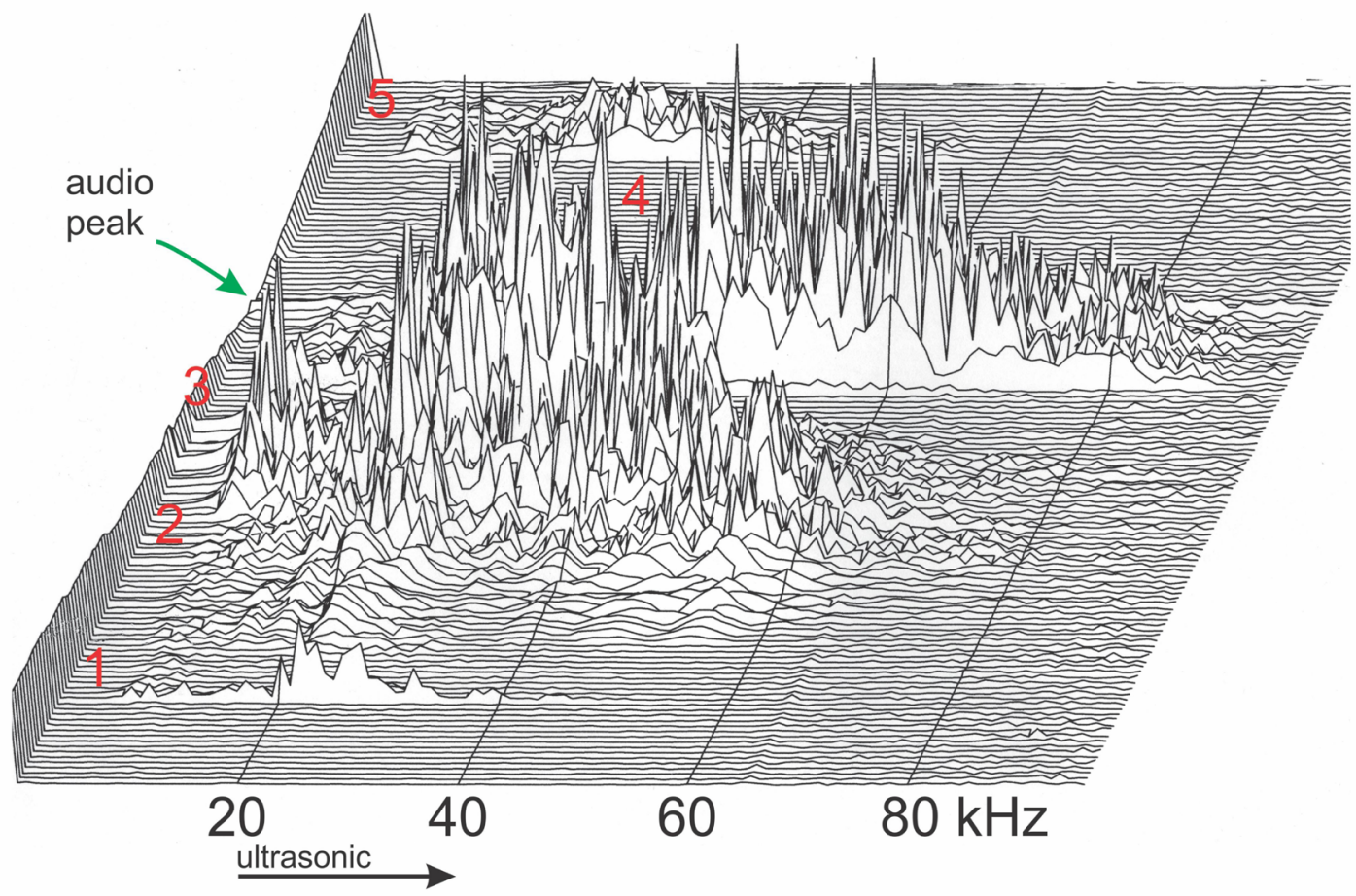

Fig. 8. Waterfall display (DADiSP, time into the page) showing frequency modulation associated with the two major trains (1-5). A waterfall display helps to make FM more apparent with band-spectrum singers like $X$. amplipennis. Specimen is as for Fig. 7 so recorded at $192 \mathrm{ks} / \mathrm{s}$. The audio peak $(\sim 8 \mathrm{kHz})$ is associated with train 2 as it becomes train 3; this peak disappears as the spectrum shifts higher $(>40 \mathrm{kHz})$ for train 4 . Trains 1,5 have effectively no ultrasonics above $40 \mathrm{kHz}$.

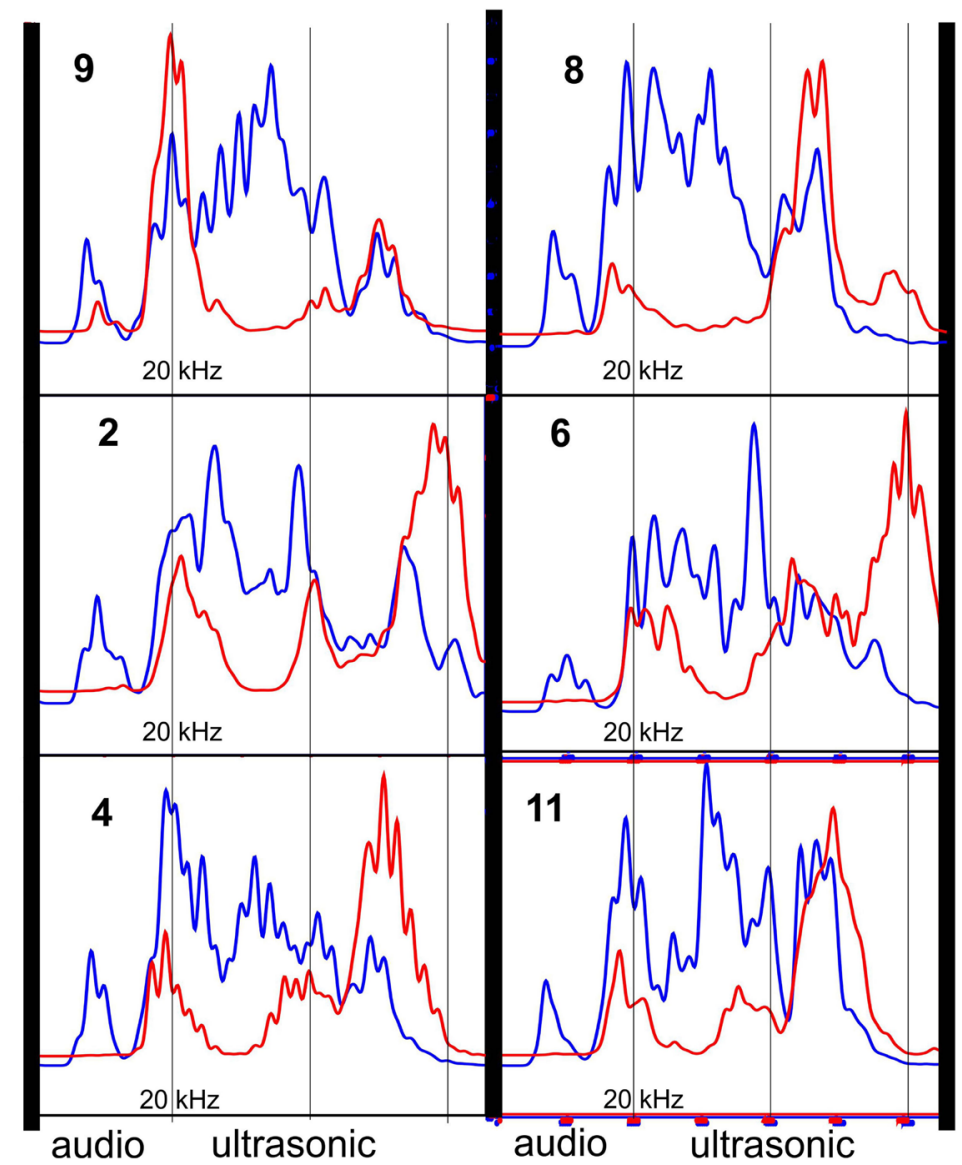

Fig. 9. Welch-smoothed (movingaverage) power spectral density estimations (DADiSP) comparing major trains $(2+3$ vs 4$)$. A 1024 -value time sample is divided into 15 segments of 128 points each, where each segment overlaps the previous by 64 points; FFT of each segment calculated and averaged. Six different specimens show interindividual variation in spectra and how each major train contributes different frequencies to the spectrum of the overall call. 
peaks with variable peak locations but this upward ultrasonic modulation is always present. Some idea of variability in peaks within the band is provided by the six spectra of Fig. 9. Blue (train $2+3$ ) spectra (note presence of $8 \mathrm{kHz}$ peak) are shown roughly overlapped in relative amplitude with train 4 (blue) spectra of the same singer: blue spectra mostly represent an upward shift including ultrasonics between 50 and $60 \mathrm{kHz}$.

Fig. 8 is a waterfall display, depicting the spectrum changes during one song, the numbers beside indicating pulse trains 1 through 5 (time advances into the display). The band spectrum of trains 2 plus 3, shows its most intense frequency peaks between 20 and $40 \mathrm{kHz}$; with train 4 this spectrum shifts markedly upward and frequency peaks between 40 and 60 come to the fore. Both the first and last pulse trains show affinity with the lower 20-40 frequency range.

\section{Natural sound levels}

Among the five measured aspects, sound levels for this dipole generator should be greatest dorsally, where the broadcast field is relatively 'free field' (free of body effects) and where the vibrating speculae, though displaced during to-fro stridulation, come closest overall to presenting normal to the plane of the microphone's condenser face. As expected the highest mean sound level measured was dorsal: $99.253 \mathrm{~dB}$ (Pa rms, $\mathrm{n}=12$ singers) at $10 \mathrm{~cm}$, the microphone barrel's long axis normal to the insect's dorsum.

The repeated measures ANOVA (sound level the dependent variable, aspect the independent) significantly rejected the null of equal mean sound levels for the five aspects $(F=48.506, p$ $<.0005)$. Sound levels were normally distributed at each aspect, as assessed by Shapiro-Wilk's test ( $p>.05)$. Mauchly's Test of Sphericity indicated the assumption of sphericity (homogeneity of variances) had not been violated $\left[\chi^{2}(9)=1.670, p=.996\right]$. (There was one outlier in the data as assessed by inspection of box plots for values greater than 1.5 box-lengths from the edge of the box; this outlier is ignored as unlikely to affect the result.)

Bonferroni-corrected post hoc pairwise comparisons were conducted. The largest decrease in sound level was seen in shifting the microphone from dorsal $(\mathrm{M}=99.253, \mathrm{SD}=1.439 \mathrm{~dB})$ to rear aspect $(M=92.351, S D=2.003 \mathrm{~dB})$, a statistically significant mean decrease of $6.901 \mathrm{~dB}$, 95\% CI [4.8-9.0], $\mathrm{p}<.0005$. Shifting from dorsal to right lateral $(\mathrm{M}=97.723, \mathrm{SD}=2.190)$, there was an average decrease of only $1.530 \mathrm{~dB}, 95 \% \mathrm{CI}[-0.437-3.496]$, nonsignificant at $\mathrm{p}=.199$. By contrast changing from dorsal to left lateral $(\mathrm{M}=96.343, \mathrm{SD}=2.202)$ there was a mean decrease of almost $3 \mathrm{~dB}(2.909 \mathrm{~dB})$ which was statistically significant 95\%CI [1.034-4.785]. Frontal aspect mean sound level was $=93.591(\mathrm{SD}=2.055)$ and this decrease, $5.66 \mathrm{~dB}, 95 \% \mathrm{CI}$ [3.6-7.8] is significantly different from dorsal $\mathrm{p}<.0005$. Comparing frontal and rear aspects, the mean difference of $1.24 \mathrm{~dB}$ is not significant 95\% [-1.08-3.56]. Comparing side-to-side differences, left lateral $(M=96.343, S D=2.202)$ vs right lateral $(M=97.72, S D 2.190)$ there was a mean nonsignificant difference of only $1.38 \mathrm{~dB}$.

In comparison to its dorsal aspect level, emitted sound decreases significantly frontally and opposite the rear opening of the subalar chamber; frontal and rear levels were comparable. Lateral aspect levels did not differ significantly from each other, but did differ re comparison to dorsal levels: shifting to aspect left lateral (side of the 'nonspecular' forewing) the level drop was significantly different from dorsal; moving to aspect right lateral (the side of the mirror-harp forewing) level drop was not different from dorsal. 


\section{Wax-Loaded costal cells}

'All-spectrum' lateral sound levels ( $\mathrm{dBPa} \mathrm{rms}$ ) are compared in Table 2 for the 6 males experimented upon: one tegminal side, either their left or right costal series, has been loaded with wax; this level at $10 \mathrm{~cm}$ is compared with the same individual's unloaded ipsilateral levels. For each reading three all-spectrum levels were measured then averaged. In two cases the unloaded sound level decreased with loading by almost $6 \mathrm{~dB}$. But in the 4 other instances the change was trivial, one down and 3 actually increasing. At best the effect of loading with wax upon the lateral broadcast at $10 \mathrm{~cm}$ was either a modest reduction in sound level $(>6 \mathrm{~dB})$ or a trivial change.

Three of these males were loaded on both costal regions with wax and dorsal sound levels recorded at $10-\mathrm{cm}$. These are compared to their original unweighted sound levels (all-spectrum) at $10-\mathrm{cm}$ distance in Table 3. Loading again saw a lowered level in all three males, down from their natural unloaded sound level, but this sound-level decrease was in all cases trivial: less than a 2-decibel drop; for two males the drop in level was < 1-dB.

Table 2. Mean all-spectrum dBPa rms lateral sound levels, 10-cm distance, measured wax-loaded and unloaded on ipsilateral side. Readings in parens on 3 different songs were averaged. Three singers show modest level drops with loading, three small level increases.

\begin{tabular}{|l|l|l|l|}
\hline $\begin{array}{l}\text { Specimen } \\
\text { number }\end{array}$ & Unloaded dBPa rms & $\begin{array}{l}\text { Loaded one side [ipsi] dBPa } \\
\text { rms }\end{array}$ & Change dBPa rms \\
\hline 2 & $\begin{array}{l}\bar{x}=97.13 \\
(97.12,97.12,97.14)\end{array}$ & $\begin{array}{l}\bar{x}=90.39 \\
(90.08,90.60,90.50)\end{array}$ & 6.74 decrease \\
\hline 3 & $\begin{array}{l}\bar{x}=94.82 \\
(94.86,94.70,94.90)\end{array}$ & $\begin{array}{l}\bar{x}=95.29 \\
(95.30,95.18,95.40)\end{array}$ & 0.47 increase \\
\hline 4 & $\begin{array}{l}\bar{x}=97.63 \\
(97.42,97.42,98.04)\end{array}$ & $\begin{array}{l}\bar{x}=96.06 \\
(95.64,96.34,96.19)\end{array}$ & 1.57 decrease \\
\hline 5 & $\begin{array}{l}\bar{x}=96.97 \\
(97.09,96.43,97.40)\end{array}$ & $\begin{array}{l}\bar{x}=92.11 \\
(91.90,91.94,92.50)\end{array}$ & 4.86 decrease \\
\hline 6 & $\begin{array}{l}\bar{x}=94.90 \\
(94.87,95.19,95.65)\end{array}$ & $\begin{array}{l}(97.49,95.70,95.02) \\
\bar{x}=99.02 \\
(97.73,99.25,98.08)\end{array}$ & 1.17 increase \\
\hline 9 & $\begin{array}{l}\bar{x}=97.30 \\
(96.91,97.89,97.08)\end{array}$ & 1.72 increase \\
\hline
\end{tabular}

Table 3. Mean all-spectrum dBPa rms dorsal sound levels, 10 -cm distance (*corrected by inverse square law calculation from $9 \mathrm{~cm}$ ), measured with both right and left costal areas natural then both wax-loaded. Readings in parens on 3 different songs, then averaged. Costal series loading has almost no effect on dorsal aspect levels.

\begin{tabular}{|l|l|l|l|}
\hline $\begin{array}{l}\text { Specimen } \\
\text { number }\end{array}$ & Unloaded & Loaded & Change dbPa rms \\
\hline 2 & $\begin{array}{l}\bar{x}=98.70 \\
(98.57,98.90,98.66)\end{array}$ & $\begin{array}{l}\bar{x}=98.47 \\
(98.60,98.36,98.49)\end{array}$ & 0.23 decrease \\
\hline 3 & $\begin{array}{l}\bar{x}=97.99 \\
(98.00,97.91,98.05)\end{array}$ & $\begin{array}{l}\bar{x}=96.33 \\
(96.53,96.14,96.30)\end{array}$ & 1.66 decrease \\
\hline 5 & $\begin{array}{l}\bar{x}=97.94 * \\
(99.00,98.68,98.89)\end{array}$ & $\begin{array}{l}\bar{x}=97.49 \\
(97.33,97.80,97.33)\end{array}$ & 0.45 decrease \\
\hline
\end{tabular}


Table 4. Mean all-spectrum dBPa rms sound levels, $10-\mathrm{cm}$ dorsal distance, measured with metawings unloaded and loaded with wax. Readings in parens on 3 different calls, then averaged. Loading has no important effect on dorsal aspect broadcast levels.

\begin{tabular}{|l|l|l|l|}
\hline $\begin{array}{l}\text { Specimen } \\
\text { number }\end{array}$ & Unloaded & Metawings loaded & Change dBPa rms \\
\hline 10 & $\begin{array}{l}\bar{x}=97.51 \\
(96.70,97.66,98.18)\end{array}$ & $\begin{array}{l}\bar{x}=100.23 \\
(101.92,99.92,98.86)\end{array}$ & 2.72 increase \\
\hline 12 & $\begin{array}{l}\bar{x}=101.77 \\
(101.72,101.76,101.83)\end{array}$ & $\begin{array}{l}\bar{x}=99.41 \\
(99.33,99.38,99.52)\end{array}$ & -2.36 decrease \\
\hline
\end{tabular}

A
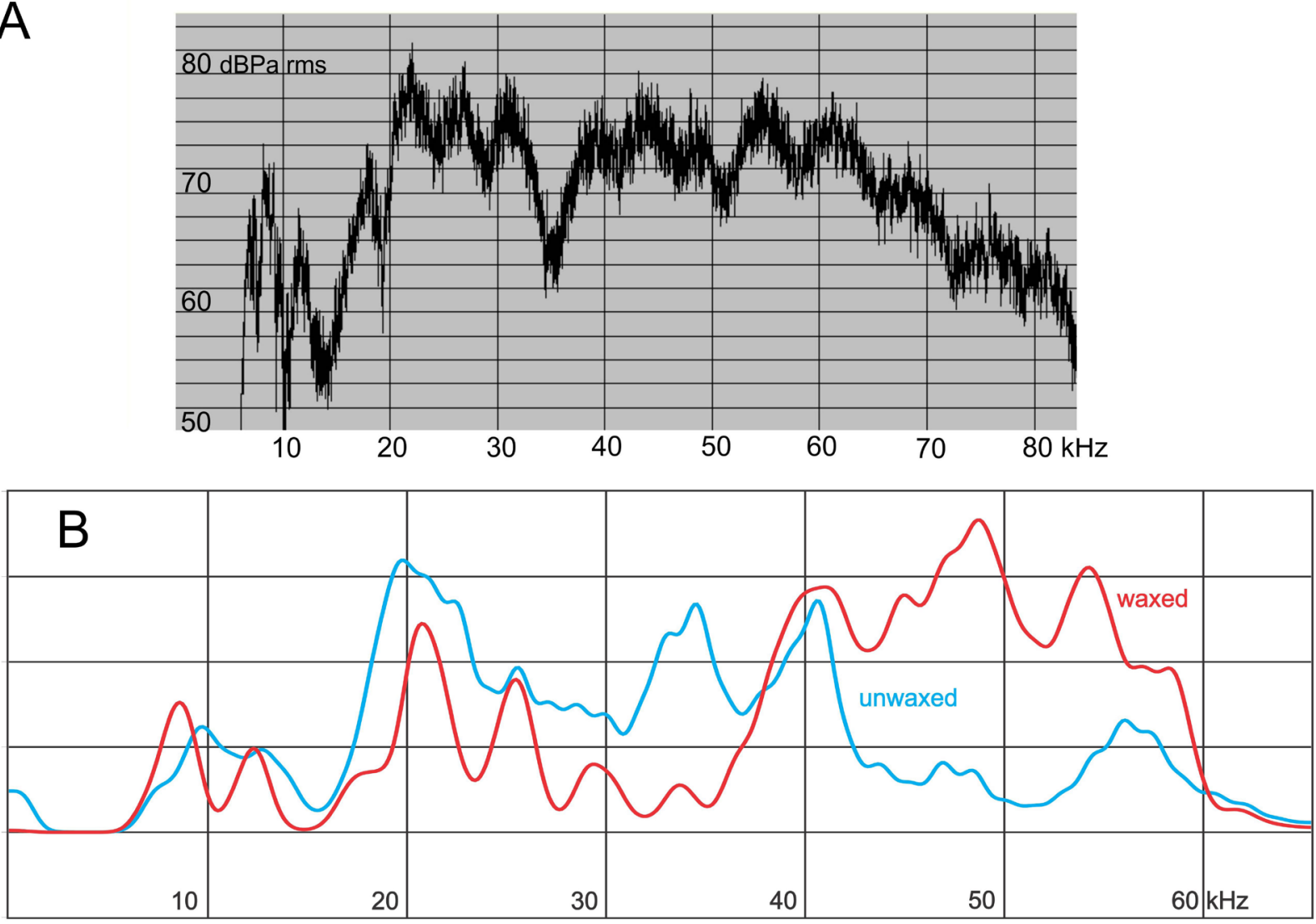

Fig. 10. Spectral breadth and wax loading. A. The ultrasonic spectrum extends from 20 well beyond $60 \mathrm{kHz}$. Averaged spectra for 20 consecutive calls (SN 13), pretriggered, originally sampled at $190 \mathrm{ks} / \mathrm{s}$, made with RTPro; each of the 20 FFTs of 16384 values with spectral lines 6400. B. Effect of wax loading on band subpeaks for time samples, based upon 4 consecutive songs of the same individual. Both spectra made $10 \mathrm{~cm}$ lateral to side where costal array was waxed. Spectra high-pass filtered at $200 \mathrm{~Hz}$, Welch-smoothed. Natural spectrum blue, wax-loaded spectrum red. Sound levels show little change, but loading has caused a shift in inharmonic spectral maxima.

For two specimens we wax-loaded the metawings where they are visible and contiguous dorsally in the midline. This operation welded the two metawings, right and left, together, as well as adding mass. The sound levels measured at $10 \mathrm{~cm}$ dorsal are given in Table 4 . One singer showed an increase of $2.7 \mathrm{~dB}$ and the other a decrease of $2.4 \mathrm{~dB}$-- again, trivial shifts in sound level.

For one specimen whose natural sound level at $10 \mathrm{~cm}$ dorsal was measured as $(97.42,97.70$, 98.76) $=97.96 \mathrm{dBPa}$ rms, metawings were completely removed, leaving the subtegminal cavity 
unpartitioned. The sound level at $10 \mathrm{~cm}$ for this operated singer was $(101.37,101.40,101.89)=$ $101.55 \mathrm{dBPa}$ rms, i.e., the insect did not show any appreciable change in sound level as a result of the operation.

For each of 6 males with their costal series wax-loaded on one side, we compared time samples of 4 sequential calls; resulting FFTs were high-pass filtered at $200 \mathrm{~Hz}$ and a moving average applied (Welch periodogram). We compared the wax-loaded spectrum, $10 \mathrm{~cm}$ lateral to the same side, with that individual's natural spectrum. By inspection we determined 5 of the 6 singers showed spectral changes as a result of loading (Fig. 10B); one seemed more or less unaffected. Energy bandwidth still extended far into the ultrasonic but the frequency peaks altered substantially between original unloaded to wax loaded. The specimen's spectra were chosen for Fig. 10 to be representative of the alterations in all 5. There was no similarity in subpeak change among the specimens, so we can only say the moving-averaged subpeaks were quite altered by the loading. We undertook a control of change in the absence of waxing manipulation. For different recording events, taken of the same unloaded individuals, 5 on the same day, one after a 4-day interval. These analyses showed no change in subpeak patterns.

\section{Discussion}

\section{Structure for a broader spectrum}

Cuticle is "praeternaturally multifunctional" (Vincent \& Wegst 2004) and easily takes on a diversity of forms to diverse ends. We infer adaptation from form and when an animal makes a sound of extreme spectral breadth, we may seek to attribute this to the peculiar forms of its cuticular generator. Oddities of form in $X$. amplipennis, such as the costal cell series, the enlarged hindwing partitioned subtegminal chamber etc. suggest ways in which morphology might have evolved in the direction of making a broader spectrum.

Based on $X$. amplipennis' generator oddities, we offer an 'evolutionary structural recipe' for making a wider spectrum. Add more radiating panels (speculae) to increase the tegminal surface area involved in sound radiation. Increase the volumes of the loading air spaces behind these cells, a necessary feature if the panels are to oscillate efficiently. Partition the subtegminal space with the metawings, creating two chambers that load and resonate in different ways to make different frequencies. Make the additional speculae diverse in thickness, dimension and stiffness, giving them more frequency-diverse resonances when excited. (Perhaps make them behave (move) differently when forces change tension within tegminal parts.) Raise generator power (force) to increase energy input to the sound. To bring a band of many frequencies rather than a single tonal peak to the same functional level, more force is required, so strengthen all the parts of the generator that translocate forces. Since the wings push against one another in shear, strengthen the bilateral symmetry of force translocation. By placing speculae at different distances from the site of force introduction, create phase differences that will diversify spectral content. Vary file-scraper stroking patterns, i.e., engage the file with the scraper in different directions at different speeds for different distances along the file: $X$. amplipennis arrives at its very wide band by combining two different less-broad spectra associated with different scraper stroking behaviours. 


\section{Force, strong veins and enlargement of the vestigial file}

Tettigoniid tegmina illustrate very well the edict of D'Arcy Thompson (1917) "the form of an object is a 'diagram' of forces". The direction, the thickness, the stiffness of tegminal veins is an indication of where forces are translocated within the structure when it generates sound.

Insects are necessarily small sound sources, a source of basic sound making inefficiency (Michelsen 1983). The form featured in this insect's generator, so different from that of other katydids, suggests evolution, within insect size constraints, to move more air and to make more sound with necessarily stronger generator parts. The stridulatory organ then becomes overall a larger sound source, effecting an improvement in impedance matching between the insect and the air (Bennet-Clark 1999).

To the 'ancestral katydid generator' $X$. amplipennis adds more moving parts and larger volumes of loading air, i.e., more reactive and resistive radiation impedances (Michelsen 1983). Force input must be greater to achieve comparably high intensity at more frequencies under additional loads: shear forces between the tegmina must be greater in this species. It is because the files, right and left, must sustain much greater reaction forces that they are so very enlarged and robust -- much more so (proportionately) than the files of conocephaline relatives, species of Orchelimum and Conocephalus.

$X$. amplipennis has evolved toward a more bilaterally balanced strength in its file veins, allowing for a greater build-up of action-reaction transverse forces. The right-tegmen file vein, $\mathrm{CuPb}$, is also strengthened through modification of its associated truss: the strong truss plus the swollen file vein form together a cuticular beam (vf of Fig 3A, 4B) alligned between scraper and wingbase. The left tegmen (ff of Fig. 3A) is strengthened in the same plane for the same reason (Fig 3A), but by the curling incorporation of a second more distad swollen vein, $\mathrm{CuPa}_{\beta}$. (Compare to the tegminal morphology of S. sphagnorum (Fig. 3B) where typical left-tegmen file structure involves just the vein $\mathrm{CuPb}$ as a tooth buttress and the $\mathrm{CuPa}_{\beta}$ vein is separate.) The vestigial file vein of the right tegmen is vestigial in name only and has thickened and enlarged to balance the strength of the left tegmen file.

Lower tooth density (Fig. 5A) in $X$. amplipennis, i.e., relatively wider spacing of file teeth, may be yet another acoustic adaptation for increased force. Power amplification by wider tooth separation is discussed by Bennet Clark (1998) in relation to Ephippiger spp. (another group of broadband making tettigoniids). Kinetic energy is gained as the scraper spends more time speeding up between "widely separated" file teeth; this kinetic energy "is dissipated on impact producing a transient sound pulse" (Bennet-Clark 1998). Wider file-tooth spaces would also allow for forces contributed by more scraper linkage distortion and 'springiness' (Patek et al. 2011).

The normally feeble file vein of a katydid right tegmen, presenting tiny nonfunctional teeth (Chamorro-Rengifo et al. 2014) is so enhanced in X. amplipennis as to raise the possibility of functionality by switching tegminal overlap. Switch-wing singing occurs in other tettigoniids (Morris et al. 1975) and especially in the related haglids (Morris \& Gwynne 1978). Switching might even help to explain the complex time-domain pattern of $X$. amplipennis: there could be a reversal in tegminal overlap at the end of the 'fro' return stroke upon one file leading to a 'to' stroke upon the file of the other wing etc. Such tegminal behaviour might account for the distinct amplitude envelopes of $2+3$ and 4 and explain the oddity that both $2+3$ and 4 pulse trains occur in succession, i.e., explain the absence of the typical amplitude modulation pattern of conocephalines: minor-major to-fro train alternation. In addition tegminal reversal might 
help explain the observed song FM.

However careful examination of the tomographic scan with switching in mind revealed no body structure on the left tegmen that could possibly engage the right tegmen file from beneath. (Fig. 6A blue arrow shows a midline body elevation also rejected as unlikely to make effective contact.) Since file teeth, though never used, are always manifest in vestigial files (ChamorroRengifo et al. 2014), one supposes selection for general enlargement, for the making of a much stronger bigger vein, could have resulted in enlarged teeth as a pleiotropic effect. We think these enlarged right-file teeth are never used.

\section{Frequency modulation}

The overall extreme-width spectrum of $X$. amplipennis' call is achieved in part, by changing within the call between two very different band spectra (Fig. 7C, Fig. 8). These two spectra are stereotyped within and between individuals. Their distinct subpeaks, coincide with distinct time-domain pulse-train patterns and with different amplitude envelopes and different pulse rates -- suggesting rather complex underlying tegminal motor movements. In the songs of many Conocephalini short low-intensity trains usually alternate with long high intensity, corresponding to 'to and fro' changes in scraper direction on the file. That in $X$. amplipennis the longest most intense trains (2 3 and 4, Fig. 7B) should occur immediately adjacent in time seems to allow no time for scraper return. It is likely complex changes in scraper direction force and speed, especially speed, underlie frequency modulation.

It is much easier to discover FM in a tonal than a band spectrum, yet the first katydid shown to frequency modulate was Conocephalus nigropleurum, a broadband-spectrum nonresonant singing conocephaline (Pipher \& Morris 1974). This species uses a simple to-fro cycle of stroking and two specimens were recorded making a $5-\mathrm{kHz}$ lowering FM on each (presumed) closing of the tegmina. A time-domain oscillogram of three complete tegminal movement cycles of $C$. nigropleurum song (Fig. 3 of op. cit.) is alligned beside a waterfall display (Fig. 4 of op. cit.), time advancing downward. As the scraper draws closer to the wing base in each cycle, the ultrasonic spectral band ( 28-55 $\mathrm{kHz}$ ) shifts lower in frequency. Whereas in $X$. amplipennis each of two different stroking cycles makes a different spectrum, in $C$. nigropleurum a different spectrum is achieved with just one simple to-fro stroking cycle.

Modest carrier frequency changes occur among crickets, happening in association with the "beginning and end of each pulse" (DeSutter-Grandcolas 1998). And some tonal tettigoniids also modulate their carrier frequency. For example, Docidocercus chlorops, a neotropical pseudophylline katydid repeats a single high-Q 60-ms wave train in the very low ultrasonic, $\sim 24 \mathrm{kHz}$ (Morris et al. 1989, see their Fig. 14). The fundamental pure-tone frequency in $D$. chlorops drops by $800 \mathrm{~Hz}$ to midtrain then climbs again $1000 \mathrm{~Hz}$ by pulse end. (The shift of its $3^{\text {rd }}$ harmonic (3 times the fundamental) is more evident than the fundamental in its more strongly curving waterfall display.)

Another example of resonant/tonal FM comes from Phaneropterinae, the largest group of Tettigoniidae and one in which nonresonant (broadband) songs are the rule (Heller \& Hemp 2014). Ectomoptera nepicauda of East Africa shifts both up and down in a series of sinusoid pulses in the high ultrasonic, between 80 and $120 \mathrm{kHz}$ (op. cit.). Yet another instance is the pseudophylline katydid Ischnomela gracilis. During the short pulse $(8 \mathrm{~ms})$ of $I$. gracilis, its carrier frequency drops by about $1 \mathrm{kHz}$ which coincides with a drop in scraper speed. Scraper speed change - varying rates of tooth contact is the basis of resonant cricket FM and is offered to explain FM in E. nepicauda and I gracilis. 


\section{Transients and translocation}

Band spectrum 'non-resonant' singers have a tooth impact rate "much lower than the carrier frequency” (Elsner \& Popov 1978) and make a series of severely damped sound 'impulses': "heavily damped oscillations" of "highly-transient, rapidly decaying wave trains" (op. cit.). These wideband singers "pulse modulate" (Broughton et al. 1975). Each transient pulse gives rise to a wide spectrum "to a whole group of frequencies, wider as the phenomenon becomes shorter" (Dumortier 1963, p.356, see his Fig. 219).

Trains of transient pulses (Fig. 7B) manifest as a broad inharmonic spectrum with spectral 'lines' that Michelsen (1983) terms "broad-band maxima”. These broadband maxima can show remarkable stability within individuals and species. For example in C. nigropleurum, for a given distance and allignment, repeatability extends beyond the broadband maxima, down to the tiniest spectral subpeaks; spectral frequencies are repeated stereotypically in each tegminal cycle, over thousands of file-run cycles (Morris \& Pipher 1967). A similar level of stability of broadband maxima is seen in acoustic grasshopper band spectra, which match species-typical spectral consistency to ear response (Meyer \& Elsner 1996).

The spectral line maxima could be altered, in effect filtered, by the substance of the tegmen as the forces spread out from the site of tooth-scraper engagement. Forces follow a path (or diagram, Thompson 1917) through the tegminal veins and cells. So e.g., with the right tegmen Fig. 4A, this path entails crossing the scraper linkage to the truss and mirror rim, then passing on to the harp, to the $\mathrm{M}+\mathrm{CuA}$, on to $\mathrm{Sc}+\mathrm{R}$ and then beyond to the costal region. Ultimately forces travel distad in the costal area along the array of costal cells. This force translocation naturally introduces a time delay which will affect the phase of emitted sounds. The costal cell series, being situated farthest along on this force path is a kind of late spectral 'filter'.

In those wax-loading experiments where we compared the effect on spectra of wax-loading the costal cell series, a substantial ultrasonic band of $20-60 \mathrm{kHz}$ remained; but for 5 of the 6 males subpeaks changed dramatically under loading. This indicates the shape of the natural broadband is affected by input from the costal cell series, that the costal area, farthest removed along the path from the tooth-scraper force input, is contributing to spectral shape. It is yet another indication that the costal series is not just functioning as a baffle, but also serves as a sound radiating surface. When loaded its thicker speculae, thicker than the mirror, were not greatly affected in their acoustic movement by loading. But there was an interesting change in spectral shape (Fig. 10B), i.e., frequencies were shifted within the band.

\section{Adding spectral frequencies by spaces}

Acoustic 'surround' spaces, embracing the tegmina proper, modelled as resonators incorporate two reactive elements: a compliance and an inertance (Bennet-Clark 1999). The interaction of these elements determines "the frequency in insect sound-producing mechanisms" (op. cit.). $X$. amplipennis' rear subalar cavity seems to show the form of a 'classic' Helmholtz resonator. Perhaps the fluid air of the subalar cavity acts as a compliance, spring-like, to the mass-like inertance of the posterior neck air. But in this insect, this supposed resonating rear cavity does not "vibrate at or near a single frequency" (op. cit.): instead it is part of a stridulum that puts energy into many frequencies over a unusually wide band. On the basis of observed output the rear cavity could be contributing to nearly every ultrasonic frequency between 20 and $60 \mathrm{kHz}$ (Fig. 10).

But in some morphological respects the rear cavity of $X$. amplipennis is unlike a 'classic' 
Helmholtz resonator. Helmholtz analysed sound frequencies by bringing brass 'eggs' (necked at one-end) of different sizes to his ear. Listening through a hole at the non-neck end, he could analyse a tone by the excited activity of the compliant air cavity when the neck air was stimulated at the appropriate incoming sound frequency. The sides of this insect's rear cavity, the costal series, are cantilevered compound membranes with a potential lateral mobility unlike a metal 'egg'. Rather, in this respect the $X$. amplipennis rear cavity better ressembles a two-headed drum or 'tom tom' of “indefinite pitch" (Rossing 2000).

A tom-tom "conveys only a weak sense of pitch" (op. cit.), i.e., its spectral output is broadband. The two opposing membranes of the drum represent a 'two-mass vibrator' in which there is "both acoustical and mechanical interaction between the two heads". In the drum two normal modes of vibration are established. In one instance the "masses move in the same direction and [in] another, at a higher frequency... they move in opposite directions" (Rossing 2000). This simple model offers a hypothetical basis for ways in which a two-mass vibrator could contribute more frequencies to spectral output.

\section{Costal array as both baffle and radiator}

The costal cell array of $X$. amplipennis, hanging down into contact with the insect's pleura, is positioned to serve as an acoustic baffle. This is the understood role of tegminal costal areas in other tettigoniids (Braun, Chamorro-Rengifo \& Morris 2009). The two sides of a sound-radiating plate produce sound waves exactly out of phase, making for destructive interference at plate edges. But "if the acoustic situation can be modified to impart some asymmetry [to this dipole] and thus some monopole component, then the output can be considerably increased" (p.238, Fletcher 1992). Sound cancellations in the plane of the panel are reduced if tegminal costal areas "impart some asymmetry" - which it would seem the costal series of katydids in general and X. amplipennis in particular, must do.

Cuticle is also "praeternaturally functional" (Vincent \& Wegst 2004) at higher resolution, i.e., at tissue level. A baffle and a speculum are functional opposites: a baffle keeps sound out of the air, minimizes radiation, lessens reverberation; speculae do the opposite: introduce sound waves into air, enhance radiation and perhaps even increase reverberation. Baffle cuticle is typically thick, opaque, inhomogeneous, blood-suffused, heavy, flaccid, bent upon itself and without tension; it drapes down upon the tergites like a curtain, forestalling short-circuiting. The contrasting cuticle of sound-radiating diaphragms, of mirrors and harps -- specular cuticle -- is relatively stiff, thin and flat, confined to a plane, homogenous and even perhaps under tension (sometimes when torn, a mirror shows stress lines). It is often transparent and the relative transparency of $X$. amplipennis' costal cells suggested to us a possible function for them in sound radiation: as some sort of secondary speculae or perhaps something baffling certain frequencies and radiating others.

Transparency is not a diagnostic feature of sound radiators. Typophyllum leaf mimics (Braun 2015) illustrate the distinction between transparency and translucency in cuticular diaphragms. Speculae among species of this genus vary in thickness and transparency in association with the tonal nature of a species' output (Braun 2015). In species where the Q of the pure-tone spectrum is higher, the speculum is stiffer and translucent rather than transparent. Broader banded spectra are apparently associated with fully transparent speculae. The same linkage is seen in species of Panacanthus (Montealegre \& Morris 2004). A thinner more transparent speculum may vibrate more readily in intrinsic frequency modes, whereas thicker and perhaps 
more uniform (in cuticular substructure) speculae lend themselves to being driven by successive generator inputs (Braun 2015).

Though not quite the window-glass transparency of a typical harp or mirror speculum (Figs $1 \mathrm{~B}, 3 \mathrm{~B}$ ), the costal cell cuticle of $X$. amplipennis has a transparency that shows clearly the dorsum in a backlit animal (Fig. 1D). In its thickness the mirror (region 1 of Fig. 3A) of $X$. amplipennis is $<3$ microns, an extremely thin double (because of the outgrowth embyrogeny of wings) cuticular layer. The costal cells (region 6 of Fig. 3A) are almost five (4.8) times thicker than the mirror (Table 1), but are still substantially thinner than the (perhaps acoustically unmodified?) archedictyon tegminal regions (region 5 of Fig. 3A); these latter range in thickness up to $>28$ microns. $X$. amplipennis' costal cells being semitransparent, homogeneous and relatively stiff, their 'traditional' function in baffling might be considered modified rather than replaced.

The very intense lateral measured sound levels are consistent with costal-cell contribution to sound radiation. Sound levels at $10 \mathrm{~cm}$ to the right and left sides of this insect measure in the high nineties, $96.3 \mathrm{~dB}$ to the left, 97.7 to the right; these readings compare very closely to 99.3 $\mathrm{dB}$ dorsally. ${ }^{1}$ While there was no lateral level enhancement relative to dorsal, as we anticipated per the morphology of the costal cell series, neither was there any substantial drop in level. One would suppose that by their positioning the costal cells must still baffle the primary speculae (mirror, harp), acting to minimize edge cancellation of their sound radiation.

Wax loading the costal series of one side showed no great effect upon lateral sound levels (Table 2). Some levels were down (5-7 dB), more or less as expected under a hypothesis of the costal series as radiators, some were slightly up $(<1.7 \mathrm{~dB})$, but there were no dramatic level changes. For the two insects measured dorsally at $10 \mathrm{~cm}$, with both right and left costal series loaded, the change in $\mathrm{dB}$ level was trivial. And loading of the metawings in two males had likewise ambiguous and trivial effects. If the costal series with their thicker cells contribute as sound radiators, additional mass does not much impair their ability to radiate sound. In this species we think the costal region is both baffle and radiator.

$X$. amplipennis shows the usual tettigoniid form asymmetry between right and left tegmina: the mirror-harp homologous cells of the file (left) tegmen are thick and opaque. This strong structural difference seems to manifest itself in a small right-left asymmetry of the broadcast field. The Bonferroni-corrected post hoc pairwise comparisons showed a nonsignificant mean $1.5 \mathrm{~dB}$ decrease shifting between dorsal and right lateral. But shifting between dorsal and left lateral, there was a significant decrease of almost $3 \mathrm{~dB}$.

\section{Broadband as adaptation}

Knowing the distance to a conspecific is critically important for katydids. Male calls are shown, by speaker phonotaxis, to draw females (e.g., Morris et al. 1978) over long and short distances. They are also shown, by speaker phonotaxis, to affect the singing-territory distance of rivals (e.g., Morris 1972), i.e., males use their songs to space themselves (e.g., Chamorro-R J et al. 2007). Tettigoniid calls transfer information to conspecifics at a distance, conspecific females localizing mates, conspecific males localizing rivals, and spectral components, propagating differentially, can code for distance (Lewis et al. 1975, Morris 1978, Forrest et al. 2006, Robillard et al. 2015).

This is the "degradation for ranging" hypothesis of Wiley \& Richards (1978). It applies

\footnotetext{
${ }^{1}$ Whether these values are elevated relative to the dorsal-aspect levels of other conocephaline spp. is not yet determined. Of special interest would be species of Conocephalus or Orchelimum.
} 
to shorter ranges and perhaps less so longer ranges. Many acoustic animals are not calling at interindividual distances that "place strong constraints on the structure of their signals for longrange communication. An individual might do better to produce a signal that degraded during transmission in ways that allowed the receiver to judge its distance" (op. cit.). In other words callers in close proximity are selected more for assessment of close-range proximity than for maximizing communication distance. Vegetation plays a critical role in this. Spectral shape will code for distance because higher frequencies travel less effectively through vegetation than lower. Using ultrasonic wavelengths will create a coding mechanism more sensitive to a neighbour's trespass. One should look for "features of signals that [correlate] with the expected spacing of individuals in relation to the degradation of signals in a particular habitat" (op. cit.).

The multiple-frequency 'noisiness' of broadband signals and a presumed lack of spectral stereotypy (not so, see above re C. nigropleurum's spectrum), encourage the view that broadband spectra are a mere effect (Otte 1974). But band spectra are very common in tettigoniids. "The songs of most bush crickets are of this general type" (Bennet-Clark 1998) and band spectra are the rule in the largest tettigoniid subfamily, Phaneropterinae (Heller \& Hemp 2014). We suggest that band spectra are not effects, but adaptive in distance ranging of rivals and mates and further, that species in the tribe Conocephalini, to which $X$. amplipennis belongs, seem to have specialized in this adaptation.

The genus Conocephalus is speciose: 100+ names are available (Eades et al. 2015). Only a small fraction of Conocephalus species have had their spectral features analysed and published, but all these, as well as several species, recorded but unpublished by GKM, have ultrasonic band spectra (Morris 1965, Morris \& Pipher 1967, Morris \& Fullard 1983, Guerra \& Morris 2002). Known Conocephalus songs share a "noisy spectrum of carrier frequencies, continuous from the low audio to beyond $100 \mathrm{kHz} .$. [incorporating] a more intense energy band between 28 and 50 $\mathrm{kHz}$ " (Morris \& Fullard 1983).

Habitats of Conocephalus spp. are often moist low fields or wetlands, e.g., swamps, swales, fens, marshes, bogs -- places filled with dense herbaceous plants such as grasses, sweet flag, rice cutgrass, rushes, sedges etc. Males typically perch and sing within this dense vegetation, using a sound channel that is occluded and cluttered. Sounds at shorter wavelengths will be increasingly poorer at transiting such vegetation. And where territory and spacing are important short ultrasonic wavelengths could create a steeper more effective indicator of trespass. Densities can be very high in Conocephalus spp.: a large population of Conocephalus nigropleurum in upper New York State were monitored in 1966 in sedge habitat; at season peak 327 singers occurred in $780 \mathrm{~m}^{2}$ a density of 42 per $100 \mathrm{~m}^{2}$ (Morris 1965). We suppose that among Conocephalus spp., Orchelimum spp., Odontoxiphium etc. and of course $X$. amplipennis, selection has favoured signalling distance to conspecifics.

Good physiological evidence that broadband spectra change within vegetation with distance is provided via the European katydid Tettigonia viridissima (Römer \& Lewald 1992). Its broadband spectrum (Fig. 3.5 of Römer 1998) changes shape dramatically between $5 \mathrm{~m}$ and $30 \mathrm{~m}$. Using a portable omega interneuron preparation, Römer and Lewald showed: "sound attenuation in excess of the attenuation due to geometrical spreading alone, increased with increasing frequency, distance between sender and receiver, and decreasing height [of the sound source] within the vegetation". Diffraction (scattering) by vegetation and air turbulence produces excess attenuation of sound, advancingly so for upward ultrasonics. The singer's habitat, the "transmission channel acts essentially as a low-pass filter" (Römer 1998).

Coding for distance by degradation is not the only basis for band-spectrum adaptiveness. 
Broadband spectra can be a way of overcoming noise: they will buffer against "variability in the received signal" (Römer \& Lewald 1992). Using multiple frequencies can reduce the chance of signal loss due to the many environmental attenuating and degrading factors (wind, signals of other species, refraction, scattering etc.); band spectra increase the chance that some frequencies will get through. Tettigoniid songs are also so redundantly structured in the time domain as to enable signal averaging (Scheidt 1973) - an hypothesis that awaits its tests.

\section{Acknowledgements}

Glenn Morris thanks Andrew Veglio, Univ. of Toronto Mississauga electronics technician, for his input over many years, and in particular for design and construction of the wax-heating device. Sara Jane Gutierrez is responsible for morphological insight into katydid sound generators. Maria Marta Cigliano facilitated our field work in Argentina. 


\section{References}

Bennet-Clark H.C. 1998. Size and scale effects as constraints in insect sound communication. Phil. Trans. R. Soc. Lond. 353: 407-419.

Bennet-Clark H.C. 1999. Resonators in insect sound production: how insects produce loud pure-tone songs. J. exp. Biol. 202: 3347-3357.

Bethoux O. 2012. Grylloptera -- a unique origin of the stridulatory file in katydids, crickets, and their kin (Archaeorthoptera). Arth. Syst. Phyl.: 70: 43-68.

Braun H. 2015. Little walking leaves from southeast Ecuador: biology and taxonomy of Typophyllum species (Orthoptera, Tettigoniidae, Pterochrozinae). Zootaxa 4012: 1-32.

Braun H., Chamorro-Rengifo J., Morris, GK. 2009. Curious katydids from the Andes of Colombia and Ecuador: three new species, a new genus and acoustic baffles. J. Orthoptera Res. 18: 225-235.

Broughton W.B., Samways M.J., Lewis D.B. 1975. Low-frequency sounds in non-resonant songs of some bush crickets (Orthoptera, Tettigonioidea). Ent. exp. \& appl. 18: 44-54.

Caudell A.N. 1906. The Locustidae and Gryllidae collected by W.T. Foster in Paraguay. Proc. US Nat. Mus. 30: $235-244$.

Chamorro-R. J. 2007. Determinants of male spacing behaviour in Panacanthus pallicornis (Orthoptera: Tettigoniidae). Ethology 113: 1158-1172.

Chamorro-Rengifo J., Braun H., Lopes-Andrade C. 2014. The secret stridulatory file under the right tegmen in katydids (Orthoptera, Ensifera, Tettigonioidea). Zootaxa 3821: 590-596.

Dumortier. B. 1963. The physical characteristics of sound emissions in Arthropoda, pp. 346-373. In Busnel, R-G. (Ed.) Acoustic Behaviour of Animals. Elsevier, Amsterdam.

Eades D.C., Otte D., Cigliano M.M., Braun H. 2015. Orthoptera Species File Online Version 5.0/5.0. Available from: http://Orthoptera.SpeciesFile.org (accessed 12 Dec. 2015).

Elsner N., Popov A.V. 1978. Neuroethology of acoustic communication. Adv. Insect Physiol., 13: 229-355.

Fletcher N. H. 1992. Acoustic Systems in Biology. Oxford Univ. Press, New York, Oxford.

Forrest T.G., Lajoie, D.R., Cusick D. 2006. Calling songs, duets, and auditory tuning in two cryptic katydids (Tettigoniidae: Phaneropterinae: Amblycorypha). Ann. Ent. Soc. Amer. 99: 978-987.

Fullard J.H., Morris G.K., Mason A.C. 1989. Auditory processing in the black-sided meadow katydid Conocephalus nigropleurum (Orthoptera: Tettigoniidae). J. comp. Physiol. A 164: 501-512.

Guerra P.A., Morris G.K. 2002. Calling communication in meadow katydids (Orthoptera, Tettigoniidae): female preferences for species-specific wingstroke rates. Behaviour 139: 23-43.

Gutierrez S-J. 2015. On the morphological adaptations of the thorax of Sphagniana sphagnorum (Ensifera, Tettigoniidae) that enable complex stridulation via the forewings. M.Sc. Thesis, University of Toronto, Toronto.

Gwynne D.T. 2001. Katydids and Bush-crickets, Reproductive Behavior and Evolution of the Tettigoniidae. Cornell University Press, Ithaca, London. 
Heller K.-G., Hemp C. 2014. Fiddler on the tree -- a bush-cricket species with unusual stridulatory organs and song. PLoS ONE 9(3): e92366. doi: 10.1371/journal.pone.0092366.

Lewis D.B., Seymour C., Broughton W.B. 1975. The response characteristics of the tympanal organs of two species of bush cricket and some studies of the problem of sound transmission J. comp. Physiol. 104: $325-351$

Meyer J., Elsner N. 1996. How well are frequency sensitivities of grasshopper ears tuned to species-specific song spectra? J. exp. Biology 199: 1631-1642.

Michelsen A. 1983. Biophysical basis of sound communication, pp. 3-38. In Lewis B. (Ed.) Bioacoustics, a Comparative Approach. Academic Press, London.

Montealegre-Z. F, Morris GK. 1999. Songs and systematics of some Tettigoniidae from Colombia and Ecuador I. Pseudophyllinae (Orthoptera). J. Orthoptera Research 8: 163-236.

Montealegre-Z. F, Morris G.K. 2004. The spiny devil katydids, Panacanthus Walker (Orthoptera: Tettigoniidae): an evolutionary study of acoustic behaviour and morphological traits. Syst. Entomol. 29: 21-57.

Montealegre-Z. F, Mason A.C. 2005. The mechanics of sound production in Panacanthus pallicornis (Orthoptera: Tettigoniidae: Conocephalinae): the stridulatory motor patterns. J. exp. Biology 208: 1219-1237.

Montealegre-Z.F., Morris G.K., Mason A.C. 2006. Generation of extreme ultrasonics in rainforest katydids. J. exp. Biol. 209: 4923-4937.

Montealegre-Z, F. 2009. Scale effects and constraints for sound production in katydids (Orthoptera: Tettigoniidae): correlated evolution between morphology and signal parameters. J. evol. Biology 22: 355-366.

Montealegre-Z F. 2012. Reverse stridulatory wing motion produces highly resonant calls in a neotropical katydid (Orthoptera: Tettigoniidae: Pseudophyllinae). J. Ins. Physiol. 58:116-124.

Morris G. K. 1965. Ultrasonic frequency analyses of Tettigoniidae. MSc Thesis. Cornell University, Ithaca.

Morris G.K.,Pipher R.E.1967.Tegminal amplifiers and spectrum consistencies in Conocephalus nigropleurum (Bruner), Tettigoniidae. J. Ins. Physiol. 13:1075-1085.

Morris G. K. 1971. Aggression in male conocephaline grasshoppers (Tettigoniidae). Anim Behav 19: 132137.

Morris GK. 1972. Phonotaxis of male meadow grasshoppers (Orthoptera: Tettigoniidae). J. NY Entomol. Soc. 80: 5-6.

Morris G.K., Aiken R.B., Kerr G.E. 1975. Calling songs of Neduba macneilli and N. sierranus (Orthoptera: Tettigoniidae: Decticinae). J. NY Entomol. Soc. 83: 229-234.

Morris GK, Kerr GE, Fullard JH. 1978. Phonotactic preferences of female meadow katydids (Orthoptera: Tettigoniidae: Conocephalus nigropleurum). Can. J. Zool. 56: 1479-1487.

Morris G.K., Gwynne D.T. 1978. Geographical distribution and biological observations of Cyphoderris (Orthoptera: Haglidae) with a description of a new species. 85: 147-167. 
Morris G.K., Fullard J.H. 1983. Random noise and congeneric discrimination in Conocephalus (Orthoptera: Tettigoniidae). In Gwynne D.T., Morris G.K. (Eds) Orthopteran mating systems, sexual competition in a diverse group of insects. Westview, Boulder, Colorado.

Morris G.K., Klimas DE, Nickle DA. 1989. Acoustic signals and systematics of false-leaf katydids from Ecuador (Orthoptera, Tettigoniidae, Pseudophyllinae). Trans. Am. Entomol. Soc. 114: 215-264.

Morris G.K. 2008. Size and carrier in the bog katydid, Metrioptera sphagnorum (Orthoptera: Ensifera, Tettigoniidae). J. Orthoptera Research 17: 333-342.

Otte, D. 1974. Effects and functions in the evolution of signaling systems. Ann. Rev. Ecol. System. 5: 385417.

Patek S.N., Dudek D.M., Rosario M.V. 2011. From bouncy legs to poisoned arrows: elastic movements in invertebrates. J., exp. Biol. 214: 1973-1980.

Pipher R.E., Morris G.K. 1974. Frequency modulation in Conocephalus nigropleurum, the black-sided meadow katydid (Orthoptera: Tettigoniidae). Can. Ent. 106: 997-1001.

Rehn J.A.G. 1907. Orthoptera of the families Tettigoniidae and Gryllidae from Sapucay, Paraguay. Proc. Acad. Nat. Sci. Phil. 59: 370-395.

Römer H. 1998. The sensory ecology of acoustic communication in insects, pp. 63-96. In Hoy R.R., Popper A.N., Fay R.R. (Eds) Comparative Hearing: Insects. Springer-Verlag, New York, Berlin, Heidelberg.

Robillard T., ter Hofstede H.M., Orivel J, Vicente N.M. 2015. Bioacoustics of the neotropical Eneopterinae (Orthoptera, Grylloidea, Gryllidae). Bioacoustics 24: 123-143.

Römer H., Lewald J. 1992. High-frequency sound transmission in natural habitats: implications for the evolution of insect acoustic communication. Behav. Ecol. Sociobiol. 29: 437-444.

Rossing T.D. 2000. Science of Percussion Instruments, vol. 3. R.J. Weiss (Ed.) Series in Popular Science, Singapore.

Schleidt W.M. 1973. Tonic communication: continual effects of discrete signs in animal communication systems. J. theor. Biol. 42: 359-386.

Thompson, D’Arcy. 1917. On Growth and Form. Cambridge, Cambridge University Press.

Torre-Bueno A.1962. Glossary of Entomology and Supplement A. Brooklyn Ent Soc, Brooklyn, $3^{\text {rd }}$ printing.

Vincent JFV, Wegst UGK. 2004. Design and mechanical properties of insect cuticle. Arth. Structure and Development 33: 187-189.

Walker TJ. 1962. Factors responsible for intraspecific variation in the calling songs of crickets. Evolution 16: 407-428.

Wiley R.H., Richards D.G. 1978. Physical constraints on acoustic communication in the atmosphere: implications for the evolution of animal vocalizations. Behav. Ecol. Sociobiol. 3: 69-94. 